Review

\title{
Recent Advances in Ocular Drug Delivery Systems
}

\section{Noriyuki Kuno * and Shinobu Fujii}

Research and Development Center, Santen Pharmaceutical Co., Ltd., 8916-16 Takayama-cho, Ikoma-shi, Nara 630-0101, Japan; E-Mail: shinobu.fujii.19@gmail.com

* Author to whom correspondence should be addressed; E-Mail: noriyuki.kuno@ gmail.com; Tel.: +81-743-79-4508; Fax: +81-743-79-4518.

Received: 2 November 2010; in revised form: 9 December 2010 / Accepted: 31 December 2010 / Published: 6 January 2011

\begin{abstract}
Transport of drugs applied by traditional dosage forms is restricted to the eye, and therapeutic drug concentrations in the target tissues are not maintained for a long duration since the eyes are protected by a unique anatomy and physiology. For the treatment of the anterior segment of the eye, various droppable products to prolong the retention time on the ocular surface have been introduced in the market. On the other hand, direct intravitreal implants, using biodegradable or non-biodegradable polymer technology, have been widely investigated for the treatment of chronic vitreoretinal diseases. There is urgent need to develop ocular drug delivery systems which provide controlled release for the treatment of chronic diseases, and increase patient's and doctor's convenience to reduce the dosing frequency and invasive treatment. In this article, progress of ocular drug delivery systems under clinical trials and in late experimental stage is reviewed.
\end{abstract}

Keywords: eye; drug delivery systems; ocular barriers; intravitreal implant

\section{Introduction}

The eye-ball is an organ protected from exogenous substances and external stress by various barriers (Figure 1), therefore, therapeutic drugs must be transported across several protective barriers regardless of which administration route is utilized, such as eye-drops, and subconjunctival, sub-tenon's and intravitreal injection and/or implant. 
Figure 1. Schematic of the eye-ball structure.

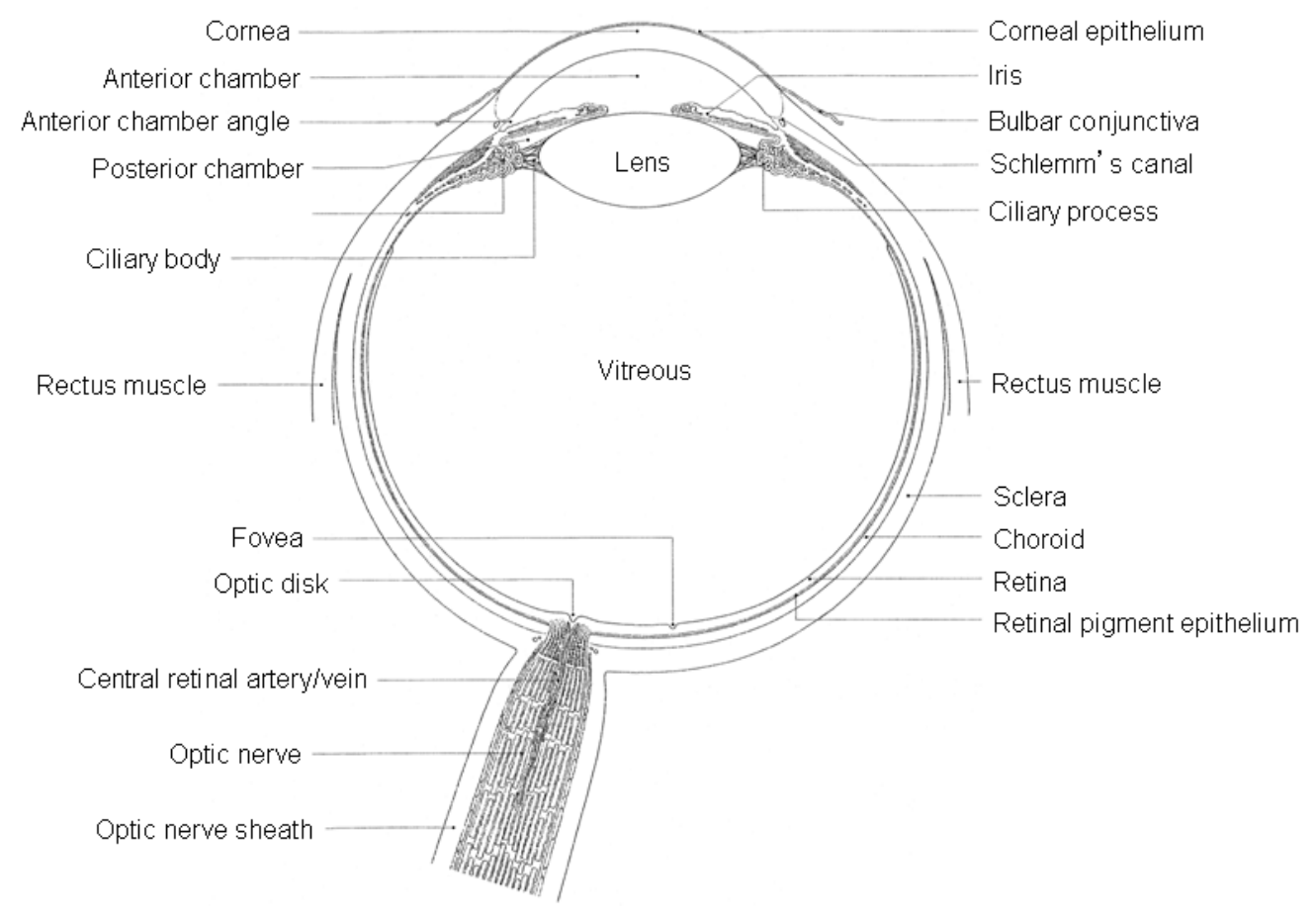

For the treatment of the anterior segment of the eye (cornea, conjunctiva, sclera, anterior uvea), usually topical ocular eye-drops are used. An eye-drop, irrespective of the instilled volume, often eliminates rapidly within five to six minutes after administration, and only a small amount (1-3\%) of an eye-drop actually reaches the intraocular tissue [1]. Thus, it is difficult to provide and maintain an adequate concentration of drug in the precorneal area. More than $75 \%$ of applied ophthalmic solution is lost via nasolachrymal drainage and absorbed systemically via conjunctiva, hence ocular drug availability is very low [2]. To increase ocular bioavailability and prolong the retention time on the ocular surface, numerous ophthalmic vehicles such as viscous solutions, suspensions, emulsions, ointments, aqueous gels, and polymeric inserts, have been investigated for topical application to the eye.

In general, topical applied drugs do not reach the posterior segment of the eye (retina, vitreous, choroid), therefore, systemic administration, periocular or intraocular injections of drugs are normally applied in clinical therapeutics $[3,4]$. However, the unique anatomy and physiology of the eye and its protective barriers prevent the administrated drugs from penetrating into the target tissues. Currently there is also rapidly growing interest in drug delivery systems (DDSs) to the posterior segment of the eye. This trend is toward a polymeric depot system implanted or injected directly into the vitreous, to obtain long-term, sustained release of drugs, as described in Figure 2.

Compliance is also problematic, particularly among patients who have chronic diseases such as glaucoma and refractory chorioretinal diseases, including uveitis, macular edema, neovascular (wet) and atrophic (dry) age-related macular degeneration (AMD), and retinitis pigmentosa (RP). It has been reported nearly $50 \%$ of glaucoma patients discontinued all topical ocular hypotensive therapy within six months [5]. Comparatively, for the treatment of neovascular AMD and macular edema secondary to retinal vein occlusion (RVO), standard therapy is intravitreal injections of ranibizumab, an 
anti-vascular endothelial growth factor (VEGF) monoclonal antibody fragment (Lucentis ${ }^{\circledR}$, Genentech, Inc., South SanFrancisco, CA, U.S.) once a month [6]. The monthly cost of Lucentis ${ }^{\circledR}$ is about $\$ 2,000$ and that means effective treatment by Lucentis ${ }^{\circledR}$ faces a serious social problem [7-9]. In addition, frequent intravitreal injections might cause complications, such as endophthalmitis and retinal detachment. Therefore, DDSs for increasing patient's and doctor's convenience are also urgently needed.

Figure 2. Example of intravitreal drug delivery systems for vitreoretinal diseases. Adapted from Kuno, N.; Fujii, S. Biodegradable intraocular therapies for retinal disorders. Drugs Aging 2010, 27, 117-134. with permission from Adis, a Wolters Kluwer business (C) Adis Data Information BV 2010. All rights reserved, by permission from Informa Healthcare: Current Eye Research [10], copyright 2010).

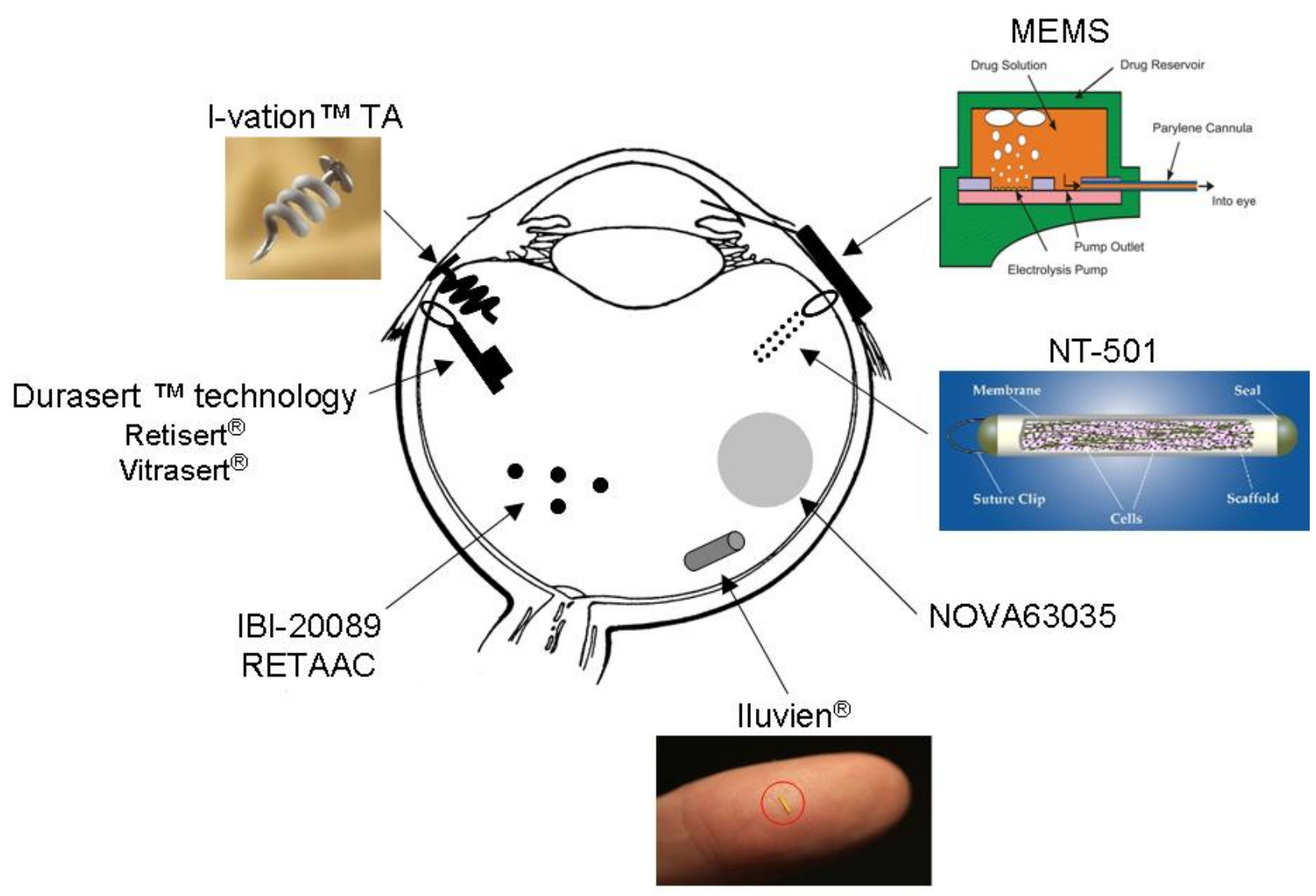

Ozurdex

In this article, the function of ocular barrier systems is described and then progress of ocular DDSs under clinical trials and in late experimental stage are reviewed. The summaries of ocular DDSs are represented in Table 1 for anterior segment and Table 2 for posterior segment. 
Table 1. Current and future drugs in clinical trials for anterior DDSs.

\begin{tabular}{|c|c|c|c|c|c|}
\hline Active ingredient & Brand name & Dosage form & $\begin{array}{l}\text { Release-controlling } \\
\text { excipient }\end{array}$ & Target Indication & $\begin{array}{l}\text { Developmental } \\
\text { stage }\end{array}$ \\
\hline Azithromycin & AzaSite $^{\circledR}$ & Eye-drops & Polycarbophil & Bacterial conjunctivitis & Launched \\
\hline $\begin{array}{l}\text { Azithromycin/Dexamethasone } \\
\text { (ISV-502) }\end{array}$ & AzaSite Plus ${ }^{\mathrm{TM}}$ & Eye-drops & Polycarbophil & Blepharoconjunctivitis & P3 \\
\hline $\begin{array}{l}\text { Bromfenac } \\
\text { (ISV-303) }\end{array}$ & - & Eye-drops & Polycarbophil & Post cataract surgery & $\mathrm{P} 1 / 2$ \\
\hline Timolol maleate & Rysmon $^{\circledR}$ TG & Eye-drops & Methylcellulose & Glaucoma & Launched \\
\hline Betaxolol & 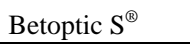 & Eye-drops & Amberlite ${ }^{\circledR}$ IRP-69 & Glaucoma & Launched \\
\hline Tobramycin/Dexamethasone & TobraDex $^{\circledR} \mathrm{ST}$ & Eye-drops & Xanthan gum & Blepharitis & Launched \\
\hline Timolol maleate & Timoptic-XE $^{\circledR}$ & Eye-drops & Gellan gum & Glaucoma & Launched \\
\hline- & Cationorm $^{\circledR}$ & Eye-drops & Cationic emulsion & Mild dry eye & Launched \\
\hline $\begin{array}{l}\text { Cyclosporine } \\
\text { (NOVA22007) }\end{array}$ & - & Eye-drops & Cationic emulsion & $\begin{array}{l}\text { Dry eye } \\
\text { Vernal keratoconjunctivitis }\end{array}$ & $\begin{array}{l}\mathrm{P} 3 \\
\mathrm{P} 2 / 3\end{array}$ \\
\hline Ketotifen & - & Soft contact lens & - & Allergic conjunctivitis & P3 \\
\hline Latanoprost & - & Puctal plug & - & Glaucoma & $\mathrm{P} 2$ \\
\hline Bimatoprost & - & Puctal plug & - & Glaucoma & $\mathrm{P} 2$ \\
\hline $\begin{array}{l}\text { Cyclosporine } \\
(\mathrm{LX} 201)\end{array}$ & - & $\begin{array}{l}\text { Episcleral } \\
\text { implant }\end{array}$ & Silicone & Aeratoconjunctivitis & P3 \\
\hline Latanoprost & - & $\begin{array}{l}\text { Subconjunctival } \\
\text { insert }\end{array}$ & PLGA/PVA & Glaucoma & P1 \\
\hline $\begin{array}{l}\text { Dexamethasone phosphate } \\
\text { (EGP-437) }\end{array}$ & EyeGate II $^{\circledR}$ & Iontophoresis & - & $\begin{array}{l}\text { Dry eye } \\
\text { Anterior uveitis }\end{array}$ & $\begin{array}{l}\text { P3 } \\
\text { P2 }\end{array}$ \\
\hline
\end{tabular}

PLGA: poly(lactide-co-glycolide), PVA: poly(vinyl alcohol).

Table 2. Current and future drugs in clinical trials for posterior DDSs.

\begin{tabular}{|c|c|c|c|c|c|}
\hline Active ingredient & Brand name & Dosage form & $\begin{array}{l}\text { Release-controlling } \\
\text { excipient }\end{array}$ & Target Indication & $\begin{array}{l}\text { Developmental } \\
\text { stage }\end{array}$ \\
\hline Ganciclovir & Vitrasert $^{\circledR}$ & IVT, implant & EVA/PVA & $\mathrm{CMV}$ retinitis & Launched \\
\hline Fluocinolone acetonide & Retisert $^{\circledR}$ & IVT, implant & Silicone/PVA & Posterior uveitis & Launched \\
\hline \multirow{2}{*}{ Fluocinolone acetonide } & \multirow{2}{*}{ Iluvien $^{\circledR}$} & \multirow{2}{*}{ IVT, implant } & \multirow{2}{*}{ Polyimide/PVA } & DME & P3 \\
\hline & & & & Wet AMD & $\mathrm{P} 2$ \\
\hline \multirow{3}{*}{ Dexamethasone } & \multirow{3}{*}{ Ozurdex $^{\circledR}$} & \multirow{3}{*}{ IVT, implant } & \multirow{3}{*}{ PLGA } & CRVO & \\
\hline & & & & BRVO & Launched \\
\hline & & & & Posterior uveitis & \\
\hline \multirow{2}{*}{ Brimonidine } & \multirow{2}{*}{-} & \multirow{2}{*}{ IVT, implant } & \multirow{2}{*}{ PLGA } & Dry AMD & P2 \\
\hline & & & & $\mathrm{RP}$ & $\mathrm{P} 1 / 2$ \\
\hline Triamcinolone acetonide & I-vation ${ }^{\mathrm{TM}} \mathrm{TA}$ & IVT, implant & PMMA/EVA & DME & $\mathrm{P} 2$ \\
\hline CNTF & \multirow{2}{*}{-} & \multirow{2}{*}{ IVT, implant } & \multirow{2}{*}{$\begin{array}{l}\text { Semipermeable } \\
\text { membrane/ARPE-19 }\end{array}$} & $\mathrm{RP}$ & $\mathrm{P} 2 / 3$ \\
\hline (NT-501) & & & & Dry AMD & $\mathrm{P} 2$ \\
\hline \multirow{2}{*}{$\begin{array}{l}\text { Triamcinolone acetonide } \\
\text { (IBI-20089) }\end{array}$} & \multirow{2}{*}{-} & \multirow{2}{*}{ IVT, injection } & \multirow{2}{*}{ Oil } & CRVO & \multirow{2}{*}{$\mathrm{P} 1$} \\
\hline & & & & BRVO & \\
\hline $\begin{array}{l}\text { Triamcinolone acetonide } \\
\text { (RETAAC) }\end{array}$ & - & IVT, injection & PLGA & DME & $\mathrm{P} 1 / 2$ \\
\hline $\begin{array}{l}\text { Corticosteroid prodrug } \\
\text { (NOVA-63035) }\end{array}$ & Cortiject $^{\circledast}$ & IVT, injection & Emulsion & DME & $\mathrm{P} 1$ \\
\hline Verteporfin & Visudyne $^{\circledR}$ & IV, injection & Liposome & Wet AMD & Launched \\
\hline Difluprednate & Durezol $^{\mathrm{TM}}$ & Eye-drops & Emulsion & DME & Off-label \\
\hline
\end{tabular}

AMD: age-related macular degeneration, ARPE-19: human retinal pigment epitheliums cells, BRVO: branch retinal vein occlusion, CMV: cytomegalovirus, CNTF: ciliary neurotrophic factor, CRVO: central retinal vein occlusion, DME: diabetic macular edema, EVA: ethylene-vinyl acetate copolymer, IV: Intravenous, IVT: intravitreal, PLGA: poly(lactide-co-glycolide), PMMA: poly(methyl methacrylate), PVA: poly(vinyl alcohol), RP: retinitis pigmentosa. 


\section{Barriers to Restrict Intraocular Drug Transport}

\subsection{Tear}

One of the precorneal barriers is tear film which reduces the effective concentration of the administrated drugs due to dilution by the tear turnover (approximately $1 \mu \mathrm{L} / \mathrm{min}$ ), accelerated clearance, and binding of the drug molecule to the tear proteins. In addition the dosing volume of instillation is usually $20-50 \mu \mathrm{L}$ whereas the size of cul-de-sac is only $7-10 \mu \mathrm{L}$. The excess volume may spill out on the cheek or exit through the nasolacrimal duct [11-13]. For details of structure and function of tear film see [14].

\subsection{Cornea}

The cornea consists of three layers; epithelium, stroma and endothelium, and a mechanical barrier to inhibit transport of exogenous substances into the eye [15] (Figure 3). Each layer possesses a different polarity and a rate-limiting structure for drug permeation. The corneal epithelium is of a lipophilic nature, and tight junctions among cells are formed to restrict paracellular drug permeation from the tear film. The stroma is composed of an extracellular matrix of a lamellar arrangement of collagen fibrils. The highly hydrated structure of the stroma acts as a barrier to permeation of lipophilic drug molecules. Corneal endothelium is the innermost monolayer of hexagonal-shaped cells, and acts as a separating barrier between the stroma and aqueous humor. The endothelial junctions are leaky and facilitate the passage of macromolecules between the aqueous humor and stroma [16].

Figure 3. Schematic of corneal structure and its cellular organization of various transport-limiting barriers. (Adapted from Cornea, 2nd Edition, vol 1. Nishida T. Cornea, Page 4. Copyright Elsevier 2005).

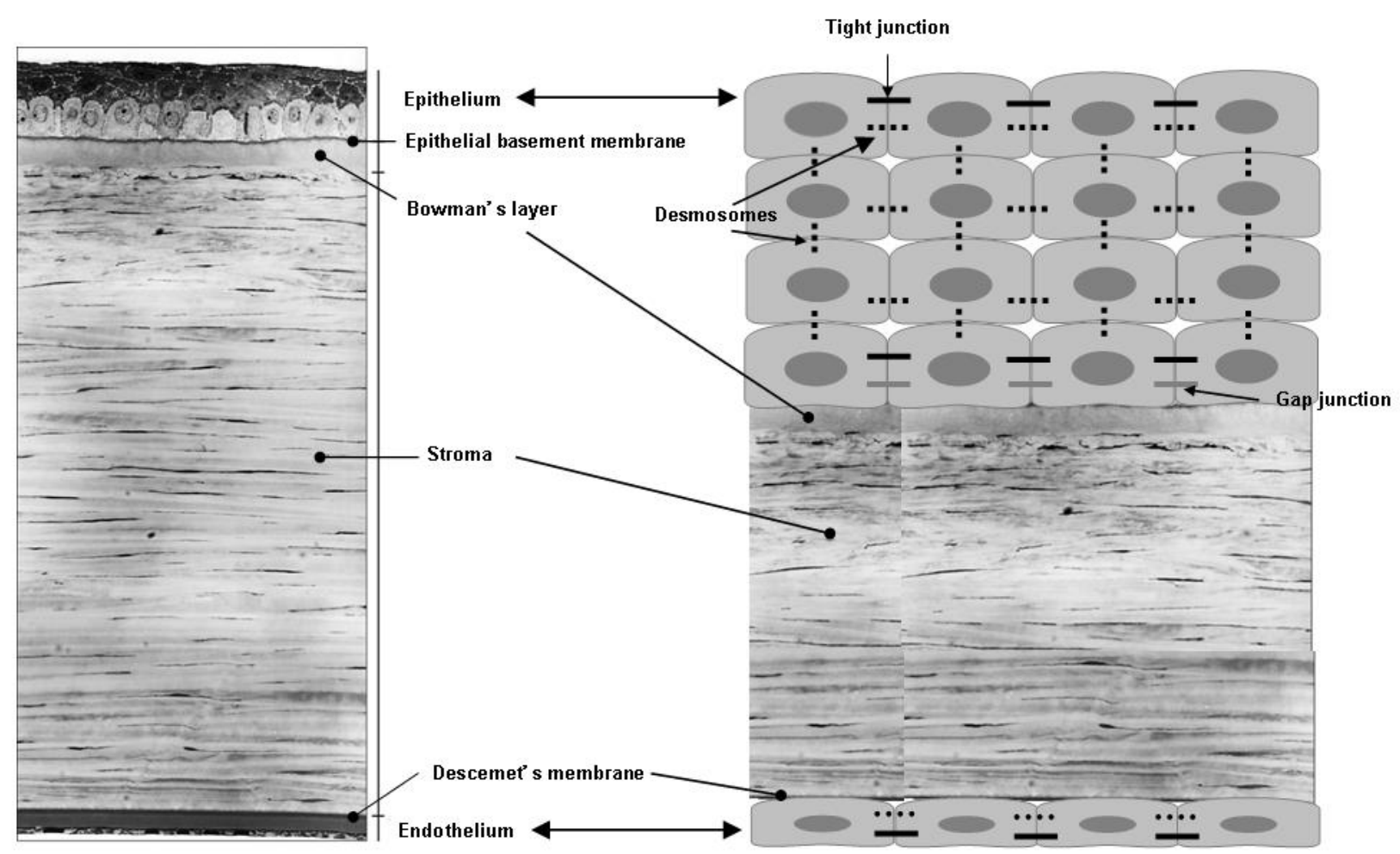




\subsection{Conjunctiva}

Conjunctiva of the eyelids and globe is a thin and transparent membrane, which is involved in the formation and maintenance of the tear film. In addition, conjunctiva or episclera has a rich supply of capillaries and lymphatics [17-19] (Figure 4); therefore, administrated drugs in the conjunctival or episcleral space may be cleared through blood and lymph. The conjunctival blood vessels do not form a tight junction barrier [20], which means drug molecules can enter into the blood circulation by pinocytosis and/or convective transport through paracellular pores in the vascular endothelial layer.

The conjunctival lymphatics act as an efflux system for the efficient elimination from the conjunctival space. Recently, it has been reported that at least $10 \%$ of a small molecular weight hydrophilic model compound (sodium fluorescein), administered in the subconjunctival space, is eliminated via the lymphatics within the first hour in rat eyes [21]. Therefore, drugs transported by lymphatics in conjunction with the elimination by blood circulation can contribute to systemic exposure, since the interstitial fluid is returned to the systemic circulation after filtration through lymph nodes.

Figure 4. Shematic representations of subconjunctival or episcleral blood vessels, and lymphatics network. (Adapted from Robinson MR, Lee SS, Kim H, et al. A rabbit model for assessing the ocular barriers to the transscleral delivery of triamcinolone acetonide, Exp. Eye Res. 2006, 82, 479-487. with permission from Elsevier Inc., and The Human Eye with permission from Sinauer Associates, Inc., copyright 1999).
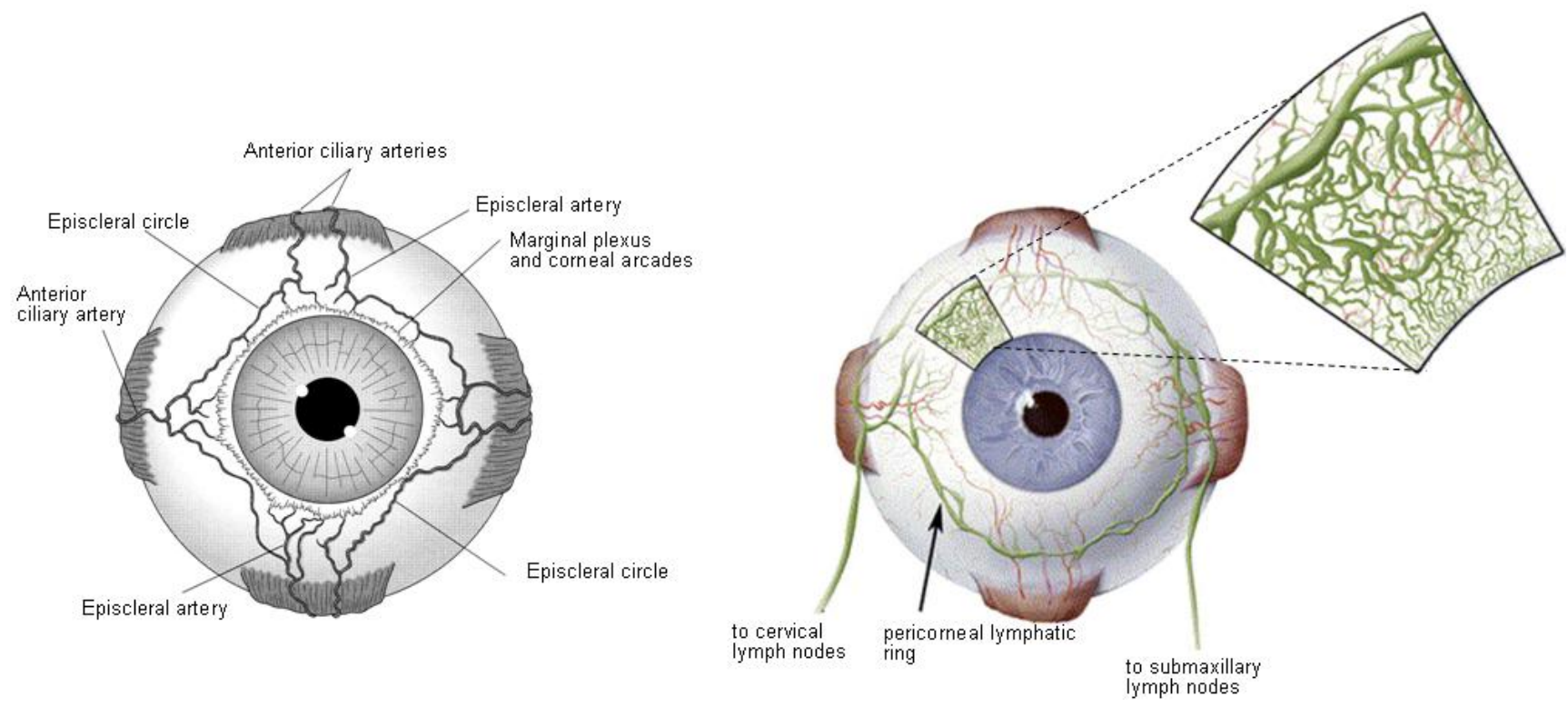

\subsection{Sclera}

The sclera mainly consists of collagen fibers and proteoglycans embedded in an extracellular matrix [22]. Scleral permeability has been shown to have a strong dependence on the molecular radius; scleral permeability decreases roughly exponentially with molecular radius [23]. Additionally, the posterior sclera is composed of a looser weave of collagen fibers than the anterior sclera [24], and the human sclera is relatively thick near the limbus $(0.53 \pm 0.14 \mathrm{~mm})$, thin at the equator $(0.39 \pm 0.17 \mathrm{~mm})$, 
and much thicker near the optic nerve $(0.9-1.0 \mathrm{~mm})$. Thus, the ideal location for transscleral drug delivery is near the equator at $12-17 \mathrm{~mm}$ posterior to the corneoscleral limbus [25]. Hydrophobicity of drugs affects scleral permeability; increase of lipophilicity shows lower permeability; and hydrophilic drugs may diffuse through the aqueous medium of proteoglycans in the fiber matrix pores more easily than lipophilic drugs [26,27].

Furthermore, the charge of the drug molecule also affects its permeability across the sclera. Positively charged compounds may exhibit poor permeability due to their binding to the negatively charged proteoglycan matrix [28].

\subsection{Choroid/Bruch's Membrane}

Choroid is one of the most highly vascularized tissues of the body to supply the blood to the retina. Its blood flow per unit tissue weight is ten-fold higher than in the brain. In addition the choroidal capillary endothelial cells are fenestrated and, in humans, are relatively large in diameter $(20-40 \mu \mathrm{m})$ (Figure 5).

Figure 5. Schematic of blood-retinal barrier, and capillary wall in the retina and the choroid.

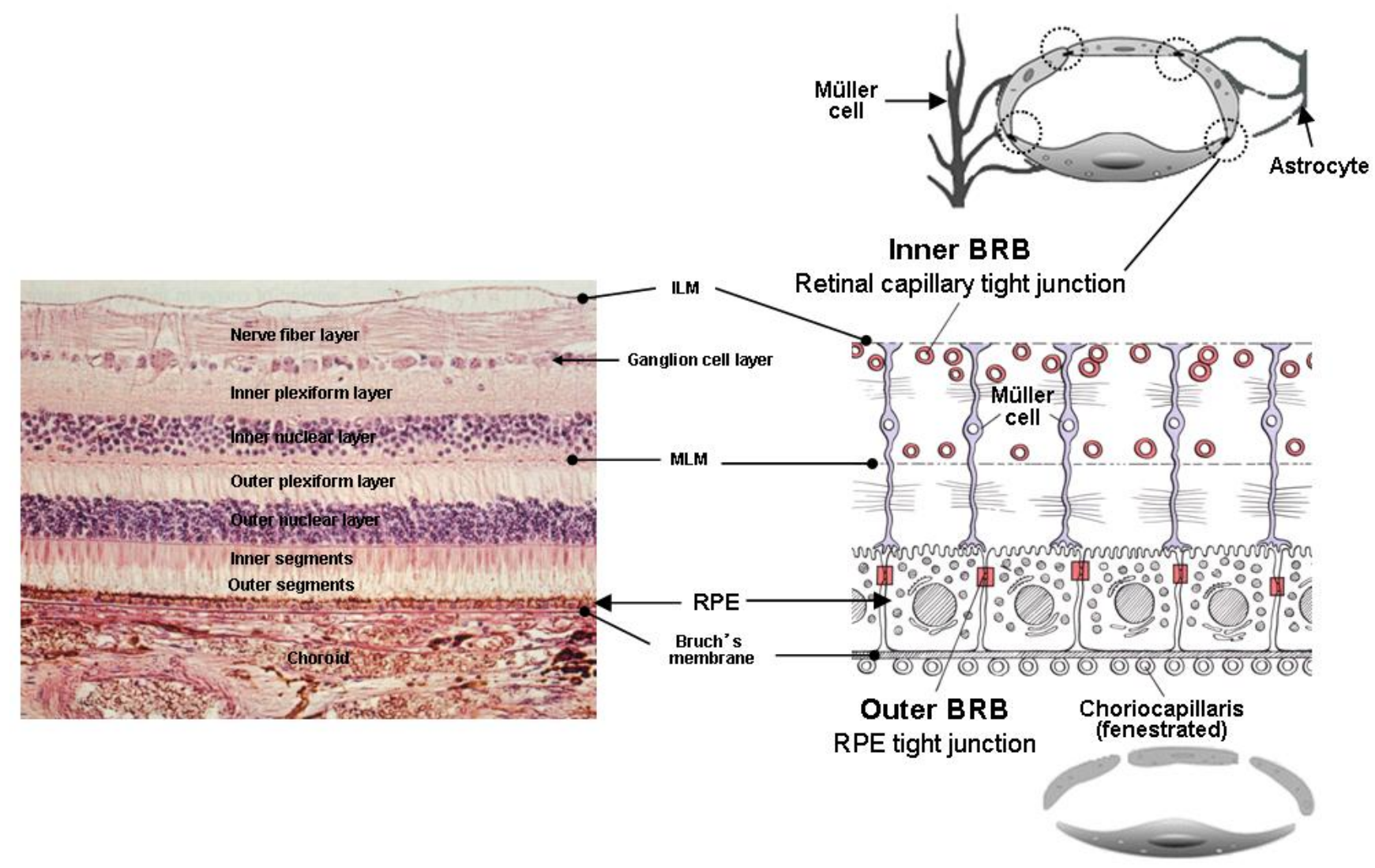

An Optical Coherence Tomography (OCT) can noninvasively measure the thickness of retina and choroid [29-32]. Using an OCT, it has been shown, choroidal thickness becomes thinner with age [33,34]. Previous histological studies have shown choroidal thickness changes from $200 \mu \mathrm{m}$ at birth decreasing to about $80 \mu \mathrm{m}$ by age 90 [35]. In addition, chorioretinal diseases including AMD 
with pigment epithelial detachment [36], central serous chorioretinopathy [37,38], age-related choroidal atrophy [39], and high myopia [40], affect choroidal thickness.

In contrast, Bruch's membrane (BM) causes thickening with age [41]. These changes cause increased calcification of elastic fibers [42], increased cross-linkage of collagen fibers [41] and increased turnover of glycosaminoglycans $[43,44]$. In addition, advanced glycation end products and lipofuscin accumulate in BM [45-47]. Thickness changes of choroid and BM might affect drug permeability from subconjunctiva or episcleral space into the retina and the vitreous.

\subsection{Retina}

The drugs in the vitreous are eliminated by two main routes from anterior and posterior segments [1]. All drugs are able to eliminate via the anterior route. This means drugs can diffuse across the vitreous to the posterior chamber and, thereafter, eliminate via aqueous turnover and uveal blood flow. Elimination via the posterior route takes place by permeation across the retina. One of the barriers restricting drug penetration from the vitreous to the retina is the internal limiting membrane (ILM) (Figure 5). The ILM separates the retina and the vitreous, and is composed of 10 distinct extracellular matrix proteins [48]. Although a previous study using primates has suggested that molecules exceeding $100 \mathrm{kDa}$ cannot cross the retinal layers into the subretinal space [49], it has been confirmed by immunohistochemical analysis, a full-length, humanized, anti-vascular endothelial growth factor (VEGF) monoclonal antibody (Bevacizumab, Avastin ${ }^{\circledR}$, Genentech Inc.), composed of 214 amino acids with a molecular weight of $149 \mathrm{kDa}$, injected into the vitreous cavity, can penetrate through the sensory retina into retinal pigment epitheliums (RPE), subretinal and choroidal space, in monkey and rabbit [50,51]. In addition, nanometer-sized particles whose mean diameter is below $200 \mathrm{~nm}$ can penetrate across the sensory retina into RPE after intravitreal injection in rabbit $[52,53]$.

In intact retina, theoretically, the drugs in the subretinal fluid could either be absorbed by the sensory retinal blood vessels or transported across the RPE, where it may be absorbed into the choroidal vessels or pass through the sclera. Drug transport across the RPE takes place both by transcellular and paracellular routes. The driving forces of outward transport of molecules from the subretinal spaces are hydrostatic and osmotic, and small molecules might transport through the paracellular inter-RPE cellular clefts and by active transport through the transcellular route [15].

\subsection{Blood-Retinal Barrier}

Blood-retinal barrier (BRB) restricts drug transport from blood into the retina. BRB is composed of tight junctions of retinal capillary endothelial cells and RPE, called iBRB for the inner and oBRB for the outer BRB, respectively [54] (Figure 5). The function of iBRB is supported by Müller cells and astrocytes.

The retinal capillary endothelial cells are not fenestrated and have a paucity of vesicles (Figure 5). The function of these endothelial vesicles has been described as endocytosis or transcytosis that may be receptor mediated or fluid phase requiring adenosine triphosphate [55,56]. A close spatial relationship exists between Müller cells and retinal capillary vessels to maintain the iBRB in the uptake of nutrients and in the disposal of metabolites under normal conditions [57,58]. Müller cells are known to support neuronal activity and maintain the proper functioning of the iBRB under normal 
conditions [59]. They are involved in the control and homeostasis of $\mathrm{K}^{+}$and other ions signaling molecules, and in the control of extracellular $\mathrm{pH}$ [60]. Dysfunction of Müller cells may contribute to a breakdown of the iBRB in many pathological conditions, such as diabetes [61]. Müller cells enhance the secretion of VEGF under hypoxic and inflammatory conditions [62,63]. In vitro study has shown that VEGF-induced occluding phosphorylation and ubiquitination causes trafficking of tight junction and leads to increased retinal vascular permeability [64].

The astrocytes originate from the optic nerve and migrate to the nerve fiber layer during development [65]. They are closely associated with the retinal capillary vessels [66,67] and help to maintain the capillary integrity [68]. Astrocytes are known to increase the barrier properties of the retinal vascular endothelium by enhancing the expression of the tight junction protein ZO-1 and modifying endothelial morphology [69].

Following systemic drug administration, drugs can easily enter into the choroid since choroid is highly vascularized tissue compared to retina. The choriocapillaris are fenestrated resulting in rapid equilibration of drug molecules present in the bloodstream with the extravascular space of the choroid. Therefore, oBRB (RPE) restricts further entry of drugs from the choroid into the retina. RPE is a monolayer of highly specialized hexagonal-shaped cells, located between the sensory retina and the choroid. The tight junctions of the RPE efficiently restrict intercellular permeation into the sensory retina.

\section{Drug Delivery Systems to Anterior Segment of the Eye}

\subsection{Eye-Drops}

To prolong the retention time of topically applied drugs, anterior DDSs for eye-drops utilizing interaction between drug carrier (excipients) and physiological environment of cornea and/or subconjunctiva are being developed.

Durasite $^{\circledR}$ DDS (InSite Vision Inc., Alameda, CA, U.S.) is based on a polycarbophil aqueous solution [70]. Polycarbophil is polyacrylic acid cross-linked with divinyl glycol, and forms hydrogen-bonding with the mucus, and corneal and conjunctival epitheliums, which are all negatively charged, to extend the effects of drug to several hours.

A broad-spectrum antibiotic, azithromycin ophthalmic solution, formulated with Durasite ${ }^{\circledR}$ (AzaSite $^{\circledR}$, Inspire Pharmaceuticals Inc., Durham, NC, U.S.) for the treatment of bacterial conjunctivitis was launched in the United States in 2007 [71]. This utilizes Durasite ${ }^{\circledR}$, a combination of azithromycin and dexamethasone (DEX) (ISV-502; AzaSite Plus ${ }^{\mathrm{TM}}$, InSite Vision Inc.), for the treatment of blepharoconjunctivitis and is currently in Phase III [72]. Bromfenac in DuraSite ${ }^{\circledR}$ (ISV-303, InSite Vision Inc.) is in Phase I/II to reduce inflammation and pain after ocular surgery [73].

Methylcellulose (MC) has a lower critical solution temperature (LCST) at approximately $50{ }^{\circ} \mathrm{C}$ [74], and sol-gel phase transition occurs. Since the temperature of ocular surface is $32-34{ }^{\circ} \mathrm{C}$ [75], LCST needs to be lower to gel MC solution at ocular surface quickly after instillation as eye-drops. In general, high concentration of electrolytes leads to salting-out and gelation of MC [74]. Wakamoto Pharmaceutical Co., Ltd. (Tokyo, Japan) has developed temperature-responsive eye-drops formulated timolol maleate for glaucoma therapy (Rysmon ${ }^{\circledR} \mathrm{TG}$ ) available in Japan, using combinations of MC, sodium citrate and polyethylene glycol, which can act by lowering LCST of MC. 
A strong cationic ion exchange resin, Amberlite ${ }^{\circledR}$ IRP-69 is polystyrene sulfonic acid resin cross-linked with divinyl benzene. Betoptic $S^{\circledR}$ marketed from 1990 (Alcon Laboratories, Inc., Fort Worth, TX, U.S.), whose active ingredient is betaxolol for glaucoma therapy, is consisted of this resin [76]. Positively charged betaxolol is bound to the negatively charged sulfonic acid groups in the resin. When betaxolol-bound resin is applied to the eye, the cationic ions such as $\mathrm{Na}^{+}$or $\mathrm{K}^{+}$in the tear fluid induce the release of betaxolol molecules from resin matrix into the tear film and lead to betaxolol penetration across the cornea [77].

TobraDex ${ }^{\circledR}$ ST (Alcon Laboratories, Inc.), a combination of tobramycin $0.3 \%$ and DEX $0.05 \%$, has been launched as an anti-inflammatory and anti-infective formulation for blepharitis [78]. It improves the suspension formulation characteristics and quality, tear film kinetics, and tissue penetration using xanthan gum, an anionic polysaccharide with repeating unit of two D-glucose, two D-mannose and one D-glucuronic acid residues [79]. The xanthan gum forms an ionic interaction with tobramycin to decrease the viscosity of the suspension compared with that normally expected from xanthan gum. The xanthan gum-tobramycin interaction reduces sedimentation of DEX particles and improves suspension characteristics. The viscosity increases after mixing with tears as the interactions between xanthan gum and tobramycin are interrupted by $\mathrm{pH}$ and the ionic content of tears. The enhanced viscosity leads longer retention and improves the ocular bioavailability of the drugs.

Gellan gum is an anionic deacetylated polysaccharide with a tetrasaccharide repeating unit of one $\alpha$-L-rhamnose, one $\beta$-D-glucuronic acid and two $\beta$-D-glucuronic acid residues. In situ gelation occurs in the presence of mono- and divalent cations including $\mathrm{Ca}^{2+}, \mathrm{Mg}^{2+}, \mathrm{K}^{+}$and $\mathrm{Na}^{+}$[80]. Timoptic-XE (Merck \& Co., Inc., Whitehouse Station, NJ, U.S.) formulated using gellan gum, is on the market, and shows administration once a day is equally effective in lowering intraocular pressure (IOP) as the equivalent concentration of simple eye-drops of aqueous solution of timolol maleate (Timoptic ${ }^{\circledR}$, Merck \& Co., Inc.) administered twice a day [81].

Novasorb $^{\circledR}$ (Novagali Pharma S.A., Evry, France) is a cationic emulsion, based on electrostatic attraction that occurs between the oily droplets of a positively-charged emulsion loaded with active

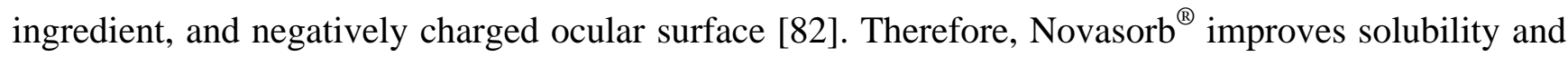
absorption of lipophilic drugs, reduces the number of instillation times and side effects, leading to better efficacy and compliance. Cationorm ${ }^{\circledR}$, which is composed of only cationic emulsion without any active ingredients, has been launched for mild dry eye [83]. NOVA22007, a cationic emulsion incorporated cyclosporine, has completed Phase III studies for dry eye [84] and Phase II/III studies for vernal keratoconjunctivitis [85].

\subsection{Contact Lens}

Soft contact lens-based DDSs have been investigated by several approaches: (1) Soak and absorption of drug solution [86]; (2) piggyback contact lens combined with a drug plate or drug solution [87]; (3) surface-modification to immobilize drugs on the surface of contact lenses [88]; (4) incorporation of drugs in a colloidal structure dispersed in the lens [89]; (5) ion ligand-containing polymeric hydrogel [90]; and (6) molecularly imprinting of drugs [91,92].

The soft contact lens based drug delivery devices are being developed by the following two companies, but details have not been disclosed. Vistakon Pharmaceuticals, LLC (Philadelphia, PA, 
U.S.) has completed a multicenter Phase III clinical trial for a contact lens presoaked to release an antihistamine drug, ketotifen, to prevent allergic conjunctivitis in contact lens wearers [93,94]. SEED Co., Ltd. (Tokyo, Japan) and Senju Pharmaceutical Co., Ltd. (Osaka, Japan) have co-developed a disposable soft contact lens to release incorporated sodium cromoglicate for one day. They have announced clinical trials for allergic conjunctivitis in Japan will be conducted in 2010 [95].

\subsection{Cul-de sac Inserts}

Ocusert $^{\circledR}$ provides uniform controlled release (20 or $40 \mu \mathrm{g} /$ hour for 7 days) of pilocarpine as an ocular hypotensive drug, and has been commercialized in 1974 [96]. Ocusert ${ }^{\circledR}$ consists of two outer layers of ethylene-vinyl acetate copolymer (EVA), and an inner layer of pilocarpine in alginate gel within di-(ethylhexyl)phthalate for a release enhancer, sandwiched between EVA layers [97]. However, Ocusert ${ }^{\circledR}$ has not become widely used because of unsatisfactory IOP control due to various causes, including difficulty of inserting the device, ejection of the device from eye, and irritation during insertion [98].

Lacrisert $^{\circledR}$ (Aton Pharma, Inc., Lawrenceville, NJ, U.S.) is a rod-shaped, water-soluble cul-de-sac insert composed of hydroxypropyl cellulose without preservatives and other ingredients $(1.27 \mathrm{~mm}$ diameter, $3.5 \mathrm{~mm}$ long), and is indicated in moderate to severe dry eye syndrome [99]. Lacrisert $^{\circledR}$ has not been applied as a drug delivery carrier as yet.

Although previously many inserts including collagen shield, Ocufit $\mathrm{SR}^{\circledR}$, New Ophthalmic Delivery System, and Minidisc ocular therapeutic system have been developed [97,100], there are no further activities at present. The commercial failure of inserts might be attributed to psychological factors including the reluctance to abandon the traditional droppable formulations, and occasional ejection from the eye observed in the case of Ocusert ${ }^{\circledR}$.

\subsection{Punctal Plugs}

To prolong the retention time and increase absorption and efficacy after instillation of eye-drops, inhibition of drainage through nasolacrimal system using punctal plug into the pancta is a long-standing approach [101]. Efficacy of an ocular hypotensitive agent in eye-drops in conjunction with punctual occlusion by punctual plug has been evaluated. Although punctal occlusion significantly decreased approximately $2 \mathrm{mmHg}$ of IOP in the plugged eyes ( $\mathrm{p}<0.001)$, it was not concluded that this IOP decrease is clinically significant $[102,103]$.

QLT Inc. (Vancouver, Canada) and Vistakon Pharmaceuticals, LLC have individually developed punctal plugs as DDSs for latanoprost and bimatoprost, respectively. QLT Inc. has reported Phase II data for a punctual plug containing a latanoprost dose of $44 \mu \mathrm{g}, 81 \mu \mathrm{g}$, and two different release rates of $95 \mu \mathrm{g}$. A retention rate based on available data from 185 eyes with 12 weeks of follow-up in conjunction with previous studies was $81 \%$, but a dose-response for IOP reduction was not observed [104]. QLT Inc. plans a clinical trial of punctal plug containing an antihistamine drug, olopatadine, for the treatment of allergic conjunctivitis.

The Phase II results of punctal plug containing bimatoprost conducted by Vistakon Pharmaceuticals, LLC has also shown no dose-response for IOP reduction [105]. 


\subsection{Subconjunctival/Episcleral Implants}

LX201 (Lux Biosciences Inc., Jersey City, NJ, U.S.) is a silicone matrix episcleral implant designed to deliver cyclosporine A to the ocular surface for one year. The implant is flat on the bottom in contact with the episclera, and the top is rounded, in contact with anterior surface. LX201 is available in two different lengths of 0.5 and 0.75 inches. Each implant is 0.08 inches wide and 0.04 inches high [106]. In preclinical studies using rabbits and dogs, the episcleral cyclosporine implant delivered continuously potentially therapeutic cyclosporine levels to the lacrimal gland, and showed efficacy in a model of keratoconjunctivitis [106,107]. Phase III study of LX201 to prevent corneal transplant rejection is now ongoing [108].

An episcleral implant developed by 3T Ophthalmics (Irvine, CA, U.S.) is also composed of silicone and looks like a tiny bathtub, less than $1.0 \mathrm{~cm}$ long. It can be re-filled with drugs in any form, such as a solution, gel or matrix [109]. In animal studies using model compound (sodium fluorescein), the episcleral implant facilitates diffusion of fluorescein through the sclera, leading to high levels in the retina and posterior vitreous, and tissue levels are markedly increased compared with periocular injection of the same amount of fluorescein [110]. At present, 3T Ophthalmics plans to enter clinical trials for retinoblastoma in the near future [109].

A subconjunctival insert containing latanoprost (Latanoprost SR insert) in Phase I clinical study developed by Pfizer, Inc. (New York, NY, U.S.) is composed of a poly (DL-lactide-co-glycolide) (PLGA) tube containing a latanoprost-core. One end of the tube is capped with an impermeable polymer, silicone, and the other end is capped with a permeable polymer, polyvinyl alcohol (PVA). Latanoprost is released across the PVA-end and its release rate is regulated by an internal diameter of PLGA tube. Duration of latanoprost release is designed for 3-6 months [111].

\section{Drug Delivery Systems to Posterior Segment of the Eye}

\subsection{Intravitreal Implants}

\subsubsection{Durasert ${ }^{\mathrm{TM}}$ Technology System}

Durasert $^{\mathrm{TM}}$ technology system (pSivida Corp., Watertown MA, U.S.) uses a drug core with one or more surrounding polymer layers, and delivers drugs for predetermined periods of time ranging from days to years. The drug release is controlled by permeability of the polymer layers [112].

Using the Durasert ${ }^{\mathrm{TM}}$ system, an antiviral drug, ganciclovir (GCV)-loaded intravitreal implant (Vitrasert $^{\circledR}$, Bausch \& Lomb Inc., Rochester, NY, U.S.) for the treatment of cytomegalovirus retinitis, has been developed as the first intravitreal DDSs that avoids systemic side effects and does not involve frequent intravitreal injections. This implant is made of EVA and PVA, and releases GCV by passive diffusion through a small opening in EVA at the base of the device for 6-8 months [113,114].

Retisert $^{\circledR}$ (Bausch \& Lomb Inc.), an intravitreal implant containing fluocinolone acetonide (FA) [115-117], is approved by FDA for the treatment of non-infectious posterior uveitis. The constitution of the implant and drug release duration are different from the above-mentioned Vitrasert ${ }^{\circledR}$. The implant contains $0.59 \mathrm{mg}$ of FA and was designed to deliver the drug for up to 1,000 days. The Retisert $^{\circledR}$ implant is composed of a central core consisting of FA compressed into a $1.5 \mathrm{~mm}$ diameter 
tablet [118]. Each FA tablet is encased in a silicone elastomer cup containing a release orifice. A semi-permeable layer of PVA coats the tablet inside the cup reservoir near the release orifice, creating a membrane between the tablet and the orifice that serves as an additional barrier for drug release from the cup. A suture tab, made from a sheet of heat cured PVA film, is attached to the silicone cup using silicone adhesive. The suture tab is used to anchor the implant in the eye through a suture hole. Both the silicone adhesive and the silicone elastomer material are impermeable to FA, while PVA is permeable to diffusion of the drug. By varying the size of the silicone elastomer cup's release orifice and the permeability of the PVA layer between the tablet and the orifice, the rate of drug release from the implant can be controlled. Release of FA from the cup reservoir occurs as water from the exterior of the implant penetrates into it and dissolves some of the drug. The dissolved drug substance then diffuses across the release orifice through the semi-permeable layer of PVA into the medium.

An injec.table, rod-shaped intravitreal implant with FA (Iluvien ${ }^{\circledR}$, Alimera Sciences, Alpharetta, GA, U.S.) (length: $3.5 \mathrm{~mm}$, diameter: $0.37 \mathrm{~mm}$ ) has been developed for the treatment of diabetic macular edema (DME). Iluvien ${ }^{\circledR}$ is made of polyimide and PVA, small enough to be injected using an inserter with a 25-gauge needle and is expected to provide sustained delivery of FA to the back of the eye for up to three years [119]. Alimera Sciences is currently conducting two Phase III pivotal clinical trials (FAME Study) for Iluvien ${ }^{\circledR}$ involving 956 patients in sites across the United States, Canada, Europe and India to assess the efficacy and safety of Iluvien ${ }^{\circledR}$ with high $(0.45 \mu \mathrm{g} / \mathrm{day})$ and low $(0.23 \mu \mathrm{g} /$ day $)$ doses [120]. The primary efficacy endpoint for the FAME Study is the difference in the percentage of patients whose best corrected visual acuity (BCVA) improved by 15 or more letters from baseline on the Early Treatment Diabetic Retinopathy Study (ETDRS) chart, at 24 months, between the treatment and control groups. The study will conclude later this year with the final patient visits at the three-year data point. Alimera Sciences has submitted a New Drug Application including the 24 month low dose data from the FAME Study to FDA in June, 2010 [121]. In addition to DME, Iluvien $^{\circledR}$ is in Phase II for the treatment of wet AMD compared to Lucentis ${ }^{\circledR}$ [122], dry AMD (geographic atrophy: GA) [123], and macular edema secondary to RVO [124].

\subsubsection{Novadur ${ }^{\mathrm{TM}}$ Technology}

Ozurdex $^{\circledR}$ (Allergan, Inc., Irvine, CA, U.S.) is an intravitreal implant containing $0.7 \mathrm{mg}$ of DEX composed of PLGA (length: $6.5 \mathrm{~mm}$, diameter: $0.45 \mathrm{~mm}$ ) approved by FDA in June, 2009 for the treatment of macular edema due to branch retinal vein occlusion (BRVO) and central retinal vein occlusion (CRVO) [125]. Ozurdex ${ }^{\circledR}$ is administered by specially designed injector with a 22-gauge needle into vitreous cavity.

Two multicenter, 6 months, sham-controlled clinical trials examined 1,267 patients with visual loss due to macular edema associated with BRVO or CRVO [126]. Patients were given a single treatment with the DEX-intravitreal implant $0.7 \mathrm{mg}(\mathrm{n}=427)$, the implant with a $0.35 \mathrm{mg}$ dose $(\mathrm{n}=414)$, or sham injection $(n=426)$. After one treatment, the time for patients to achieve a $\leq 15$-letter improvement in BCVA was significantly less in both groups receiving the DEX-intravitreal implant compared with sham-assigned patients $(\mathrm{P} \leq 0.001)$. The percentage of eyes that had a $\geq 15$-letter improvement in BCVA was significantly higher in both of the DEX-intravitreal implant groups versus sham at 30 to 90 days $(\mathrm{P} \leq 0.001)$. 
The percentage of eyes having a $\geq 15$-letter loss in BCVA was significantly lower in the groups receiving the DEX-intravitreal implant $0.7 \mathrm{mg}$ compared with sham at all follow-up visits $(\mathrm{P} \geq 0.036)$. In addition, the improvement of mean BCVA was greater in both DEX-intravitreal implant groups compared with sham at all follow-up time-points $(\mathrm{P} \geq 0.006)$. Improvements of BCVA with DEX-intravitreal implant treatment were seen in patients having BRVO and in those with CRVO, although the patterns of patient's responses differed. The percentage of eyes treated with the DEX-intravitreal implant that had an IOP $\geq 25 \mathrm{~mm} \mathrm{Hg}$ peaked at $16 \%$ at day 60 (for both doses) and was not different from the sham-eyes by day 180 . Most recently Ozurdex ${ }^{\circledR}$ has been approved by FDA for posterior non-infectious uveitis [127]. At present, Ozurdex ${ }^{\circledR}$ is in Phase III clinical trial for DME [128].

Brimonidine is a $\alpha 2$ adrenergic agonist, which can release various neurotrophins including brain-derived neurotrophic factor (BDNF) and ciliary neurotrophic factor (CNTF) [129,130]. These neurotrophins have a potential to prevent apoptosis of photoreceptors and/or RPE [131,132]. PLGA intravitreal implant with two doses $(200 \mu \mathrm{g}, 400 \mu \mathrm{g})$ of brimonidine tartrate similar to Ozurdex ${ }^{\circledR}$ is now in Phase II clinical study for dry AMD [133], and phase I/II clinical trials for RP [134] by Allergan, Inc.

\subsubsection{I-vation ${ }^{\mathrm{TM}} \mathrm{TA}$}

SurModics, Inc. (Eden Prairie, MN, U.S.) has a delivery system using I-vation ${ }^{\mathrm{TM}}$ technology to delivery triamcinolone acetonide (TA) into the vitreous. I-vation ${ }^{\mathrm{TM}}$ intravitral implant is a titanium helical coil (length; $0.5 \mathrm{~mm}$, width; $0.21 \mathrm{~mm})$ coated with TA $(925 \mu \mathrm{g})$ and non-biodegradable polymers; poly(methyl methacrylate) and EVA. It is predicted that this implant will have an in vivo sustained delivery for a minimum of two years [135]. At present, I-vation ${ }^{\mathrm{TM}}$ is in Phase I clinical trials in patients with DME and 24 months interim results were reported [136]. At 24 months, 25 of 31 patients remained in the study; 11 patients (11 eyes) in the slow-release group, 14 patients (14 eyes) in the fast-release group. The proportion of patients demonstrating improved visual acuity (greater than zero ETDRS letter gain from baseline) was $64 \%$ in the slow-release group and $72 \%$ in the fast-release group. $28.6 \%$ of patients in the fast-release group gained greater than 15 letters. The mean macular thickness, measured by OCT, decreased in the slow group from $529 \mu \mathrm{m}$ at baseline to $328 \mu \mathrm{m}$, and in the fast-release group from $376 \mu \mathrm{m}$ at baseline to $268 \mu \mathrm{m}$

\subsubsection{NT-501}

Neurotech Pharmaceuticals, Inc. (Lincoln, RI, U.S.) has been developing "Encapsulated Cell Technology", which provides extracellular delivery of CNTF through long-term and stable intraocular release at constant doses through a device implanted in the vitreous [137]. It contains human RPE cells (ARPE-19) genetically modified to secrete recombinant human CNTF. The device consists of a sealed semi-permeable membrane capsule surrounding a scaffold of six strands of polyethylene terephthalate yarn, which can be loaded with cells. The device is surgically implanted in the vitreous through a tiny scleral incision and is anchored by a single suture through a titanium loop at one end of the device. The semi-permeable membrane allows the outward diffusion of CNTF and other cellular metabolites 
and the inward diffusion of nutrients necessary to support the cell survival in the vitreous cavity while protecting the contents from host cellular immunologic attack. A Phase I clinical trial for RP has been completed and demonstrated well tolerated for 6 months implantation [138]. Eighteen month results in Phase II study for patients with GA with dry AMD were reported [139]; 48 participants were randomized in a 2:1:1 ratio to receive a high or low dose NT-501, or to sham surgery, respectively. Among eyes with baseline BCVA 20/63, the mean BCVA in the high dose group was 10.5 and 10.0 letters greater than the low dose/sham group at 12 months with statistically significant difference $(\mathrm{p}=0.03)$, and 18 months respectively. Stabilized visual acuity was accompanied by corresponding structural changes; NT-501 treatment resulted in a dose-dependent increase of retinal thickness as early as four months after implantation and this increase was maintained through 6, 12 and 18 months $(\mathrm{p}<0.001)$. The growth rate of GA lesion area was reduced in treated eyes compared to fellow eyes at 12 and 18 months.

Neurotech Pharmaceuticals, Inc. plans to initiate a Phase I study of NT-503, which releases a VEGF antagonist using "Encapsulated Cell Technology”, for neovascular AMD [140].

\subsection{Injectable Particulate Systems}

\subsubsection{IBI-20089}

Icon Bioscience, Inc. (Sunnyvale, CA, U.S.) is developing IBI-20089 containing TA using Verisome $^{\mathrm{TM}}$ drug delivery platform technology. The Verisome ${ }^{\mathrm{TM}}$ is a translucent liquid. When the IBI-20089 mixes with saline, the solution becomes a milky, slightly opaque color and forms gel. According to Icon's patent [141], IBI-20089 might be a solution of TA in biodegradable benzyl benzoate. IBI-20089 is designed to last up to one year with a single intravitreal injection. An open label, Phase I study for cystoid macular edema associated with BRVO or CRVO, has been completed [142]. Five patients received an intravitreal injection of $6.9 \mathrm{mg}$ TA in $25 \mu \mathrm{L}$, and other patients received $13.8 \mathrm{mg}$ TA in $50 \mu \mathrm{L}$ by using 28 or 30 gauge needle. For the $6.9 \mathrm{mg}$ cohort, mean central subfield thickness decreased from $477 \mu \mathrm{m}$ at baseline to $368.6 \mu \mathrm{m}$ at day 1 ( $\mathrm{p}<0.06$ ); $387 \mu \mathrm{m}$ at day $30(\mathrm{p}=0.18), 301 \mu \mathrm{m}$ at day $180(\mathrm{p}=0.18), 244 \mu \mathrm{m}(\mathrm{p}=0.47)$ day $270,251 \mu \mathrm{m}(\mathrm{p}=0.46)$ at day 360. For the $13.8 \mathrm{mg}$ cohort, mean central subfield OCT thickness decreased from $518 \mu \mathrm{m}$ at baseline to $404 \mu \mathrm{m}$ at day $1(\mathrm{p}=0.134) ; 289 \mu \mathrm{m}$ at day $30(\mathrm{p}=0.003), 207 \mu \mathrm{m}$ at day 180 $(\mathrm{p}=0.004), 276 \mu \mathrm{m}(\mathrm{p}=0.001)$ at day $270,278 \mu \mathrm{m}(\mathrm{p}=0.009)$ at day 360. IBI-20089 adjunctively with $0.5 \mathrm{mg}$ of ranibizumab (Lucentis ${ }^{\circledR}$ ) is now being tested in a Phase II clinical study for neovascular AMD [143].

\subsubsection{RETAAC}

Cardillo et al. reported human studies of PLGA microspheres with TA (RETAAC system) [144]. RETAAC was injected intravitreously into patients with diffuse DME and their efficacy compared to naked TA-injections. RETAAC-treated eyes showed marked decrease of retinal thickness as well as improved visual acuity for 12 months. This study demonstrated a superior long-term pharmacologic performance compared to naked TA-injected eyes. RETAAC was found to be safe and well tolerated by the retina. No drug or procedure related side effects were observed in this study. A Phase I/II study 
has been conducted for 21 patients with DME unresponsive laser photocoagulation and demonstrated central macular edema measured by OCT showed a reduction from baseline exceeding 59\% at 3 months after injection of RETAAC, which remained at 6 and 12 months, but significant improvement of visual acuity was not achieved.

\subsubsection{Cortiject $^{\circledR}$}

Cortiject $^{\circledR}$ (NOVA63035, Novagali Pharma S.A.) is a preservative-free emulsion composed of oily carrier and phospholipid as surfactant, encapsulating a target tissue-activated corticosteroid prodrug [145]. Released DEX palmitate is de-esterified by a retina-specific esterase, and activated to be DEX. A single intravitreal injection provides sustained release over 6-9 months. Although an open-label, Phase I study for DME is currently under way, details are not disclosed [146].

\subsubsection{Visudyne ${ }^{\circledR}$}

Liposomes can also be designed to intervene in intercellular biological responses between receptors and ligands in physiological or pathological conditions and also to receive external signals by laser beam or an electric or magnetic field [147-149]. Therefore, liposomes may become available for a drug targeting system. Visudyne ${ }^{\circledR}$ (QLT Ophthalmics, Inc., Menlo Park, CA, U.S.) is an intravenous liposomal formulation containing photosensitizer, verteporfin, in photodynamic therapy for predominantly classic subfoveal choroidal neovascularization due to AMD, pathologic myopia or presumed ocular histoplasmosis [150]. Plasma lipoproteins, such as low-density lipoprotein (LDL), have been proposed to enhance the delivery of hydrophobic verteporfin to malignant tissue since tumor cells have been shown to increase numbers of LDL receptors [151]. In addition, it is reported that liposomes composed of negatively charged phospholipids, such as phosphatidylglycerol, uptake into tumor cells by LDL receptor-mediated endocytosis [152]. It is thought that verteporfin, released in blood flow from liposome, is associated with LDL, and uptakes in neovascular tissues and undissociated verteporfin still encapsulated in liposome, is accumulated in vascular endothelial cells via LDL receptor-mediated endocytosis since phosphatidylglycerol is a major constitute of Visudyne ${ }^{\circledR}$ formulation.

\subsection{Eye-Drops}

Aqueous suspension of poorly water-soluble drugs has some pharmaceutical problems including caking and poor redispersibility, which may affect bioavailability due to dosing error, and difficulty of filtration sterilization due to the wide range of particle size. Difluprednate emulsion clears these problems, and can more easily penetrate into intraocular tissues compared with its suspension [153].

A non-randomized clinical study for refractory DME after vitrectomy, with eye-drops of difluprednate emulsion (Durezol ${ }^{\mathrm{TM}}$, Alcon Laboratories, Inc.), approved by FDA for the treatment of inflammation and pain associated ocular surgery, was conducted to compare with sub-tenon's injection of TA [154]. In the eye-drops group (11 eyes in 7 patients), mean retinal thickness measured by OCT decreased from $500.6 \pm 207.7 \mu \mathrm{m}$ at baseline to $341.2 \pm 194.8 \mu \mathrm{m}$ at 3 month. For the sub-tenon's TA group (11 eyes in 10 patients), mean retinal thickness decreased from $543.3 \pm 132.6 \mu \mathrm{m}$ at baseline 
to $378.6 \pm 135 \mu \mathrm{m}$ at 3 months. The rate of effective improvement in retinal thickness did not differ between the difluprednate eye-drops (73\%) and sub-tenon's TA (84\%) (Fisher's exact test: P=1).

\section{Physical Devices}

\subsection{Iontophoresis}

Iontophoresis is a noninvasive technique for ocular drug delivery, and therefore avoids the complications of a surgical implantation or frequent and high dose of intravitreal injections. The drug is applied with a weak direct current (DC) that drives charged molecules across the sclera and into the choroid, retina, and vitreous. A ground electrode of the opposite charge is placed elsewhere on the body to complete the circuit. The drug serves as the conductor of the current through the tissue. In the rabbit iontophoresis of DEX phosphate, DEX levels in the cornea after a single transcorneal iontophoresis for $1 \mathrm{~min}$ ( $1 \mathrm{~mA}$ ) were up to 30 fold higher compared to those obtained after frequent eye-drops instillation [155].

Eyegate Pharmaceutical, Inc. (Waltham, MA, U.S.) has begun to enroll for a pivotal Phase III study of EGP-437 for the treatment of dry eye syndrome [156]. EGP-437 is a DEX phosphate for delivery using the EyeGate II $^{\circledR}$ Delivery System. The EyeGate II $^{\circledR}$ Delivery System has been studied in many subjects and completed Phase II studies for the treatment of dry eye [157] and anterior uveitis [158].

Theoretically, iontophoresis is limited to drugs of a small size, an ionic nature and with low molecular weight, and in the case of diffusion, treatment time is passively determined by the typically slow diffusion process rather than the therapeutic need. In many cases, existing drugs need to be reformulated to confer an electric charge so that they can be utilized within the system. To resolve these problems, Macroesis ${ }^{\mathrm{TM}}$ (Buckeye Pharmaceuticals, Beachwood, OH, U.S.) propose using an alternating current instead of DC $[159,160]$.

\subsection{Micro-Electromechanical Intraocular Drug Delivery Device}

A microelectromechanical systems (MEMS) drug delivery device is investigated for the treatment of chronic and refractory ocular diseases [10,161]. MEMS device can be re-filled with the drug solution, giving long-term drug therapy which avoids repeated surgeries. The first generation of MEMS is a manually-controlled system limited by variations in the drug-release duration and force applied for depressing of the reservoir. To resolve this problem, the next generation device consists of an electrolysis chamber with electrolysis actuation to precisely delivery the desired dosage volume, a drug reservoir with refill port, battery and electronics. Biocompatible and flexible parylene is used to construct the MEMS. Battery and wireless inductive power transfer can be used to drive electrolysis. Electrolysis is a low power process in which the electrochemically-induced phase change of water to hydrogen and oxygen gas generates pressure in the reservoir forcing the drug through the cannula [10]. The reservoir is implanted in the subconjunctival space and flexible cannula is inserted through incision into the anterior or posterior segment.

Prototypes of MEMS with ocular hypotensive agents, $0.5 \%$ timolol or $0.004 \%$ travoprost, were implanted in two dogs under the temporal conjunctiva with the cannula inserted into the anterior 
chamber [162]. The reduction of IOP was continued for 8 hours, and no complications were observed for 3 months.

Replenish, Inc. (Pasadena, CA, U.S.) plans to enter trials for FDA approval this year for a refillable and programmable pump that would be implanted in the eye to feed medicine for glaucoma or AMD. The Replenish device can last more than five years before needing replacement, much longer than current treatments [163].

\section{Conclusions}

The eye is one of the most complex organs in the human body as previously mentioned in this review.

Many successes in anterior DDSs for prolonging retention time and reducing administration frequency have been achieved. Additional needs in this field might be to improve patient's and doctor's compliance.

On the other hand, many implantable sustained DDSs for chronic vitreoretinal diseases, using biodegradable or non-biodegradable polymers, are being developed. In order to reduce side-effects during long-term drug exposure, intelligent posterior drug delivery strategies, which respond to external environment changes and/or disease-oriented pathophysiological signals, are needed. Due to transparent ocular mediums, intraocular tissues (vitreous and retina) are relatively easy to be observed without invasion, and various administration approaches including intravitreal or subretinal injection/implantation could be developed. In addition to Lucentis ${ }^{\circledR}$ (monoclonal antibodies), since the eye-ball is a closed organ, novel therapeutic molecules such as an antisense oligonucleotide for cytomegalovirus retinitis, an aptamer or a small interfering RNA for neovascular AMD, have been investigated in human eye before their applications for systemic diseases. Therefore more challenging approaches might be applicable in the ophthalmic field. Certainly, we should further consider the most efficacious combinations of optimal drugs, dose, route, and drug release pattern (sustained-release, pulsatile-release, or controlled-release responding to a trigger) according to the pathophysiology and progressive courses of the targeted disease.

\section{References}

1. Maurice, D.M.; Mishima, S. Ocular pharmacokinetics. In Handbook of Experimental Pharmacology; Sears, M.L., Ed.; Springer: Berlin-Heidelberg, Germany, 1984; pp. 16-119.

2. Schoenwald, R.D. Ocular pharmacokinetics. In Textbook of Ocular Pharmacology; Zimmerman, T.J., Ed.; Lippincott-Raven: Philadelphia, PA, USA, 1997; pp. 119-138.

3. Geroski, D.H.; Edelhauser, H.F. Drug delivery for posterior segment eye disease. Invest. Ophthalmol. Vis. Sci. 2000, 41, 961-964.

4. Lee, S.S.; Hughes, P.M.; Robinson, M.R. Recent advances in drug delivery systems for treating ocular complications of systemic diseases. Curr. Opin. Ophthalmol. 2009, 20, 511-519.

5. Nordstrom, B.L.; Friedman, D.S.; Mozaffari, E.; Quigley, H.A.; Walker, A.M. Persistence and adherence with topical glaucoma therapy. Am. J. Ophthalmol. 2005, 140, 598.e1-598.e11.

6. Genentech Inc. Lucentis ${ }^{\circledR}$. Available online: http://www.gene.com/gene/products/information/ pdf/lucentis-prescribing.pdf (accessed on 18 October 2010). 
7. Martin, D.F.; Maguire, M.G.; Fine, S.L. Identifying and eliminating the roadblocks to comparative-effectiveness research. N. Engl. J. Med. 2010, 363, 105-107.

8. Gower, E.W.; Cassard, S.D.; Bass, E.B.; Schein, O.D.; Bressler, N.M. A cost-effectiveness analysis of three treatments for age-related macular degeneration. Retina 2010, 30, 212-221.

9. Patel, J.J.; Mendes, M.A.; Bounthavong, M.; Christopher, M.L.; Boggie, D.; Morreale, A.P. Cost-utility analysis of bevacizumab versus ranibizumab in neovascular age-related macular degeneration using a Markov model. J. Eval. Clin. Pract. 2010, doi: 10.1111/j.13652753.2010.01546.x.

10. Saati, S.; Lo, R.; Li, P.Y.; Meng, E.; Varma, R.; Humayun, M.S. Mini drug pump for ophthalmic use. Curr. Eye Res. 2010, 35, 192-201.

11. Mishima, S.; Gasset, A.; Klyce, S.D., Jr.; Baum, J.L. Determination of tear volume and tear flow. Invest. Ophthalmol. 1966, 5, 264-276.

12. Lee, V.H.; Robinson, J.R. Topical ocular drug delivery: Recent developments and future challenges. J. Ocul. Pharm. 1986, 2, 67-108.

13. Schoenwald, R.D. Ocular drug delivery. Pharmacokinetic considerations. Clin. Pharm. 1990, 18, 255-269.

14. Craig, J. Structure and function of the preocular tear film. In The tear film; Korb, D.R., Craig, J., Doughty, M., Guillon, J., Smith, G., Tomlinson, A., Eds.; Butterworth-Heinemann: Oxford, UK, 2002; pp. 18-50.

15. Pederson, J.E. Fluid physiology of the subretinal space. In Retina, Fourth edition; Ryan, S.J., Ed.; Elsevier Inc.: Philadelphia, PA, USA, 2006; Volume III, pp. 1909-1920.

16. Fischbarg, J. The corneal endothelium. In The Biology of Eye; Fischbarg. J., Ed.; Academic Press: New York, NY, USA, 2006; pp. 113-125.

17. Sugar, H.S.; Riazi, A.; Schaffner, R. The bulbar conjunctival lymphatics and their clinical significance. Trans. Am. Acad. Ophthalmol. Otolaryngol. 1957, 61, 212-223.

18. Gausas, R.E.; Gonnering, R.S.; Lemke, B.N.; Dortzbach, R.K.; Sherman, D.D. Identification of human orbital lymphatics. Ophthal. Plast. Reconstr. Surg. 1999, 15, 252-259.

19. Singh, D. Conjunctival lymphatic system. J. Cataract. Refract. Surg. 2003, 29, 632-633.

20. Raviola, G. Conjunctival and episcleral blood vessels are permeable to blood-borne horseradish peroxidase. Invest. Ophthalmol. Vis. Sci. 1983, 24, 725-736.

21. Lee, S.J.; He, W.; Robinson, S.B.; Robinson, M.R.; Csaky, K.G.; Kim, H. Evaluation of clearance mechanisms with trans-scleral drug delivery. Invest. Ophthalmol. Vis. Sci. 2010, 51, 5205-5212.

22. Oyster, C.W. The cornea and sclera. In The Human Eye; Oyster. C.W., Ed.; Sinauer Associates, Inc.: Sunderland, UK, 1999; pp. 325-378.

23. Ambati, J.; Canakis, C.S.; Miller, J.W.; Gragoudas, E.S.; Edwards, A.; Weissgold, D.J.; Kim, I.; Delori, F.C.; Adamis, A.P. Diffusion of high molecular weight compounds through sclera. Invest. Ophthalmol. Vis. Sci. 2000, 41, 1181-1185.

24. Curtin, B.J. Physiopathologic aspects of scleral stress-strain. Trans. Am. Ophthalmol. Soc. 1969, 67, 417-461. 
25. Myles, M.E.; Neumann, D.M.; Hill, J.M. Recent progress in ocular drug delivery for posterior segment disease: Emphasis on transscleral iontophoresis. Adv. Drug Del. Rev. 2005, 57, 2063-2079.

26. Maurice, D.M.; Polgar, J. Diffusion across the sclera. Exp. Eye Res. 1977, 25, 577-582.

27. Cruysberg, L.P.; Nuijts, R.M.; Geroski, D.H.; Koole, L.H.; Hendrikse, F.; Edelhauser, H.F. In vitro human scleral permeability of fluorescein, dexamethasone-fluorescein, methotrexate-fluorescein and rhodamine $6 \mathrm{G}$ and the use of a coated coil as a new drug delivery system. J. Ocul. Pharmacol. Ther. 2002, 18, 559-569.

28. Dunlevy, J.R.; Rada, J.A. Interaction of lumican with aggrecan in the aging human sclera. Invest. Ophthalmol. Vis. Sci. 2004, 45, 3849-3856.

29. Huang, D.; Swanson, E.A.; Lin, C.P.; Schuman, J.S.; Stinson, W.G.; Chang, W.; Hee, M.R.; Flotte, T.; Gregory, K.; Puliafito, C.A.; et al. Optical coherence tomography. Science 1991, 254, 1178-1181.

30. Schuman, J.S.; Hee, M.R.; Arya, A.V.; Pedut-Kloizman, T.; Puliafito, C.A.; Fujimoto, J.G.; Swanson, E.A. Optical coherence tomography: A new tool for glaucoma diagnosis. Curr. Opin. Ophthalmol. 1995, 6, 89-95.

31. Schuman, J.S.; Pedut-Kloizman, T.; Hertzmark, E.; Hee, M.R.; Wilkins, J.R.; Coker, J.G.; Puliafito, C.A.; Fujimoto, J.G.; Swanson, E.A. Reproducibility of nerve fiber layer thickness measurements using optical coherence tomography. Ophthalmology 1996, 103, 1889-1898.

32. Hee, M.R.; Puliafito, C.A.; Duker, J.S.; Reichel, E.; Coker, J.G.; Wilkins, J.R.; Schuman, J.S.; Swanson, E.A.; Fujimoto, J.G. Topography of diabetic macular edema with optical coherence tomography. Ophthalmology 1998, 105, 360-370.

33. Margolis, R.; Spaide, R.F. A pilot study of enhanced depth imaging optical coherence tomography of the choroid in normal eyes. Am. J. Ophthalmol. 2009, 147, 811-815.

34. Ikuno, Y.; Kawaguchi, K.; Nouchi, T.; Yasuno, Y. Choroidal thickness in healthy Japanese subjects. Invest. Ophthalmol. Vis. Sci. 2010, 51, 2173-2176.

35. Nickla, D.L.; Wallman, J. The multifunctional choroid. Prog. Retin. Eye Res. 2010, 29, 144-168.

36. Spaide, R.F. Enhanced depth imaging optical coherence tomography of retinal pigment epithelial detachment in age-related macular degeneration. Am. J. Ophthalmol. 2009, 147, 644-652.

37. Imamura, Y.; Fujiwara, T.; Margolis, R.; Spaide, R.F. Enhanced depth imaging optical coherence tomography of the choroid in central serous chorioretinopathy. Retina 2009, 29, 1469-1473.

38. Maruko, I.; Iida, T.; Sugano, Y.; Ojima, A.; Ogasawara, M.; Spaide, R.F. Subfoveal choroidal thickness after treatment of central serous chorioretinopathy. Ophthalmology 2010, 117, 1792-1799.

39. Spaide, R.F. Age-related choroidal atrophy. Am. J. Ophthalmol. 2009, 147, 801-810.

40. Fujiwara, T.; Imamura, Y.; Margolis, R.; Slakter, J.S.; Spaide, R.F. Enhanced depth imaging optical coherence tomography of the choroid in highly myopic eyes. Am. J. Ophthalmol. 2009, 148, 445-450.

41. Ramrattan, R.S.; van der Schaft, T.L.; Mooy, C.M.; de Bruijn, W.C.; Mulder, P.G.; de Jong, P.T. Morphometric analysis of Bruch's membrane, the choriocapillaris, and the choroid in aging. Invest. Ophthalmol. Vis. Sci. 1994, 35, 2857-2864. 
42. Spraul, C.W.; Lang, G.E.; Grossniklaus, H.E.; Lang, G.K. Histologic and morphometric analysis of the choroid, Bruch's membrane, and retinal pigment epithelium in postmortem eyes with age-related macular degeneration and histologic examination of surgically excised choroidal neovascular membranes. Surv. Ophthalmol. 1999, 44 Suppl 1, S10-32.

43. Hewitt, A.T.; Newsome, D.A. Altered synthesis of Bruch's membrane proteoglycans associated with dominant retinitis pigmentosa. Curr. Eye Res. 1985, 4, 169-174.

44. Hewitt, A.T.; Nakazawa, K.; Newsome, D.A. Analysis of newly synthesized Bruch's membrane proteoglycans. Invest. Ophthalmol. Vis. Sci. 1989, 30, 478-486.

45. Farboud, B.; Aotaki-Keen, A.; Miyata, T.; Hjelmeland, L.M.; Handa, J.T. Development of a polyclonal antibody with broad epitope specificity for advanced glycation endproducts and localization of these epitopes in Bruch's membrane of the aging eye. Mol. Vis. 1999, 5, 11.

46. Handa, J.T.; Verzijl, N.; Matsunaga, H.; Aotaki-Keen, A.; Lutty, G.A.; te Koppele, J.M.; Miyata, T.; Hjelmeland, L.M. Increase in the advanced glycation end product pentosidine in Bruch's membrane with age. Invest. Ophthalmol. Vis. Sci. 1999, 40, 775-779.

47. Yamada, Y.; Ishibashi, K.; Bhutto, I.A.; Tian, J.; Lutty, G.A.; Handa, J.T. The expression of advanced glycation endproduct receptors in rpe cells associated with basal deposits in human maculas. Exp. Eye Res. 2006, 82, 840-848.

48. Candiello, J.; Balasubramani, M.; Schreiber, E.M.; Cole, G.J.; Mayer, U.; Halfter, W.; Lin, H. Biomechanical properties of native basement membranes. FEBS J. 2007, 274, 2897-2908.

49. Mordenti, J.; Cuthbertson, R.A.; Ferrara, N.; Thomsen, K.; Berleau, L.; Licko, V.; Allen, P.C.; Valverde, C.R.; Meng, Y.G.; Fei, D.T.; Fourre, K.M.; Ryan, A.M. Comparisons of the intraocular tissue distribution, pharmacokinetics, and safety of 125I-labeled full-length and Fab antibodies in rhesus monkeys following intravitreal administration. Toxicol. Pathol. 1999, 27, 536-544.

50. Heiduschka, P.; Fietz, H.; Hofmeister, S.; Schultheiss, S.; Mack, A.F.; Peters, S.; Ziemssen, F.; Niggemann, B.; Julien, S.; Bartz-Schmidt, K.U.; Schraermeyer, U. The tubingen Bevacizumab study, G. penetration of Bevacizumab through the retina after intravitreal injection in the monkey. Invest. Ophthalmol. Vis. Sci. 2007, 48, 2814-2823.

51. Dib, E.; Maia, M.; Longo-Maugeri, I.M.; Martins, M.C.; Mussalem, J.S.; Squaiella, C.C.; Penha, F.M.; Magalhaes, O., Jr.; Rodrigues, E.B.; Farah, M.E. Subretinal bevacizumab detection after intravitreous injection in rabbits. Invest. Ophthalmol. Vis. Sci. 2008, 49, 1097-1100.

52. Sakurai, E.; Ozeki, H.; Kunou, N.; Ogura, Y. Effect of particle size of polymeric nanospheres on intravitreal kinetics. Ophthalmic Res. 2001, 33, 31-36.

53. Bourges, J.-L.; Gautier, S.E.; Delie, F.; Bejjani, R.A.; Jeanny, J.-C.; Gurny, R.; BenEzra, D.; Behar-Cohen, F.F. Ocular drug delivery targeting the retina and retinal pigment epithelium using polylactide nanoparticles. Invest. Ophthalmol. Vis. Sci. 2003, 44, 3562-3569.

54. Cunha-Vaz, J. The blood-ocular barriers. Surv. Ophthalmol. 1979, 23, 279-296.

55. Schnitzer, J.E.; Liu, J.; Oh, P. Endothelial caveolae have the molecular transport machinery for vesicle budding, docking, and fusion including VAMP, NSF, SNAP, annexins, and GTPases. $J$. Biol. Chem. 1995, 270, 14399-14404.

56. Simionescu, M.; Gafencu, A.; Antohe, F. Transcytosis of plasma macromolecules in endothelial cells: A cell biological survey. Microsc. Res. Technol. 2002, 57, 269-288. 
57. Tout, S.; Chan-Ling, T.; Hollander, H.; Stone, J. The role of Muller cells in the formation of the blood-retinal barrier. Neuroscience 1993, 55, 291-301.

58. Distler, C.; Dreher, Z. Glia cells of the monkey retina-II. Muller cells. Vis. Res. 1996, 36, 2381-2394.

59. Reichenbach, A.; Wurm, A.; Pannicke, T.; Iandiev, I.; Wiedemann, P.; Bringmann, A. Muller cells as players in retinal degeneration and edema. Graefes. Arch. Clin. Exp. Ophthalmol. 2007, 245, 627-636.

60. Bringmann, A.; Skatchkov, S.N.; Pannicke, T.; Biedermann, B.; Wolburg, H.; Orkand, R.K.; Reichenbach, A. Muller glial cells in anuran retina. Microsc. Res. Technol. 2000, 50, 384-393.

61. Tretiach, M.; Madigan, M.C.; Wen, L.; Gillies, M.C. Effect of Muller cell co-culture on in vitro permeability of bovine retinal vascular endothelium in normoxic and hypoxic conditions. Neurosci. Lett. 2005, 378, 160-165.

62. Eichler, W.; Kuhrt, H.; Hoffmann, S.; Wiedemann, P.; Reichenbach, A. VEGF release by retinal glia depends on both oxygen and glucose supply. Neuroreport 2000, 11, 3533-3537.

63. Kaur, C.; Sivakumar, V.; Foulds, W.S. Early response of neurons and glial cells to hypoxia in the retina. Invest. Ophthalmol. Vis. Sci. 2006, 47, 1126-1141.

64. Murakami, T.; Felinski, E.A.; Antonetti, D.A. Occludin phosphorylation and ubiquitination regulate tight junction trafficking and vascular endothelial growth factor-induced permeability. $J$ Biol. Chem. 2009, 284, 21036-21046.

65. Watanabe, T.; Raff, M.C. Retinal astrocytes are immigrants from the optic nerve. Nature 1988, 332, 834-837.

66. Schnitzer, J. Retinal astrocytes: Their restriction to vascularized parts of the mammalian retina. Neurosci. Lett. 1987, 78, 29-34.

67. Schnitzer, J. Astrocytes in the guinea pig, horse, and monkey retina: Their occurrence coincides with the presence of blood vessels. Glia 1988, 1, 74-89.

68. Zhang, Y.; Stone, J. Role of astrocytes in the control of developing retinal vessels. Invest. Ophthalmol. Vis. Sci. 1997, 38, 1653-1666.

69. Gardner, T.W.; Lieth, E.; Khin, S.A.; Barber, A.J.; Bonsall, D.J.; Lesher, T.; Rice, K.; Brennan, W.A., Jr. Astrocytes increase barrier properties and ZO-1 expression in retinal vascular endothelial cells. Invest. Ophthalmol. Vis. Sci. 1997, 38, 2423-2427.

70. InSite Vision DuraSite ${ }^{\circledR}$. Available online: http://www.insitevision.com/durasite (accessed on 18 October 2010).

71. InSite Vision AzaSite ${ }^{\circledR}$. Available online: http://www.insitevision.com/marketed_products (accessed on 18 October 2010).

72. ClinicalTrials.gov Comparative study of AzaSite plus compared to AzaSite alone and dexamethasone alone to treat subjects with blepharoconjunctivitis. Available online: http://clinicaltrials.gov/ct2/show/NCT00754949?term=Insite+Vision\&rank=2 (accessed on 18 October 2010).

73. ClinicalTrials.gov Study to compare differing dosing regimens of ISV-303 (Bromfenac in DuraSite) to xibrom and vehicle in post cataract surgery volunteers. Available online: http://clinicaltrials.gov/ct2/show/NCT01190878?term=ISV-303\&rank=1 (accessed on 18 October 2010). 
74. Wade, A.; Weller, P. Methylcellulose. In Handbook of Pharmaceutical Excipients; American Pharmaceutical Association: Washington, DC, USA, 1994; pp. 306-309.

75. Purslow, C.; Wolffsohn, J.S. Ocular surface temperature: A review. Eye Contact Lens 2005, 31, 117-123.

76. Alcon Betoptic s (betaxolol hydrochloride) Suspension Available online: http://dailymed.nlm.nih.gov/ dailymed/archives/fdaDrugInfo.cfm?archiveid=2377 (accessed on 18 October 2010).

77. Jani, R.; Gan, O.; Ali, Y.; Rodstrom, R.; Hancock, S. Ion exchange resins for ophthalmic delivery. J. Ocul. Pharm. Ther. 1994, 10, 57-67.

78. Alcon Inc Alcon launches TobraDex ${ }^{\circledR}$ ST suspension. Available online: http://invest.alconinc.com/ phoenix.zhtml?c=130946\&p=RssLanding\&cat=news\&id=1474062 (accessed on 18 October 2010).

79. Scoper, S.; Kabat, A.; Owen, G.; Stroman, D.; Kabra, B.; Faulkner, R.; Kulshreshtha, A.; Rusk, C.; Bell, B.; Jamison, T.; Bernal-Perez, L.; Brooks, A.; Nguyen, V. Ocular distribution, bactericidal activity and settling characteristics of TobraDex ${ }^{\circledR}$ ST ophthalmic suspension compared with TobraDex ${ }^{\circledR}$ ophthalmic suspension. Adv. Ther. 2008, 25, 77-88.

80. Crescenzi, V.; Dentini, M.; Coviello, T. Solutions and gelling properties of microbial polysaccharides of industrial interest: The case of gellan. In Novel Biodegradable Microbial Polymers; Dawes, E.A., Ed.; Kluwer Academic Publishers: Boston, MA, USA, 1990; pp. 227-284.

81. MERCK Timoptic-XE ${ }^{\circledR}$. Available online: http://www.merck.com/product/usa/pi_circulars/ t/timoptic/timoptic_xe_pi.pdf (accessed on 18 October 2010).

82. Novagari Pharma SA Novasorb ${ }^{\circledR}$. Available online: http://www.novagali.com/en/our-research/ novasorb/ (accessed on 18 October 2010).

83. Novagari Pharma SA Cationorm ${ }^{\circledR}$. Available online: http://www.novagali.com/en/eye-therapy/ mild-dry-eye/ (accessed on 18 October 2010).

84. ClinicalTrials.gov Double-masked trial of NOVA22007 (Ciclosporin 0.1\%) versus vehicle in patients with moderate to severe dry eye syndrome. Available online: http://clinicaltrials.gov/ ct2/show/NCT00814515?term=Novagali\&rank=2 (accessed on 18 October 2010).

85. ClinicalTrials.gov Efficacy and tolerance of Nova22007 versus vehicle in patients with vernal keratoconjunctivitis (VKC). Available online: http://clinicaltrials.gov/ct2/show/NCT00328653? term=Novagali\&rank=4 (accessed on 18 October 2010 ).

86. Peterson, R.C.; Wolffsohn, J.S.; Nick, J.; Winterton, L.; Lally, J. Clinical performance of daily disposable soft contact lenses using sustained release technology. Contact Lens Anterior Eye 2006, 29, 127-134.

87. Sano, K.; Tokoro, T.; Imai, Y. A new drug delivery system utilizing piggyback contact lenses. Acta Ophthalmol. Scand. 1996, 74, 243-248.

88. Sato, T.; Uchida, R.; Tanigawa, H.; Uno, K.; Murakami, A. Application of polymer gels containing side-chain phosphate groups to drug-delivery contact lenses. J. Appl. Polym. Sci. 2005, 98, 731-735.

89. Danion, A.; Brochu, H.; Martin, Y.; Vermette, P. Fabrication and characterization of contact lenses bearing surface-immobilized layers of intact liposomes. J. Biomed. Mater. Res. A 2007, 82, 41-51. 
90. Uchida, R.; Sato, T.; Tanigawa, H.; Uno, K. Azulene incorporation and release by hydrogel containing methacrylamide propyltrimenthylammonium chloride, and its application to soft contact lens. J. Control. Release 2003, 92, 259-264.

91. Hiratani, H.; Alvarez-Lorenzo, C. Timolol uptake and release by imprinted soft contact lenses made of N,N-diethylacrylamide and methacrylic acid. J. Control. Release 2002, 83, 223-230.

92. Xinming, L.; Yingde, C.; Lloyd, A.W.; Mikhalovsky, S.V.; Sandeman, S.R.; Howel, C.A.; Liewen, L. Polymeric hydrogels for novel contact lens-based ophthalmic drug delivery systems: A review. Contact Lens Anterior Eye 2008, 31, 57-64.

93. ClinicalTrials.gov Evaluation of efficacy and safety of an anti-allergy drug with a contact lens in allergic conjunctivitis. Available online: http://clinicaltrials.gov/ct2/show/NCT00432757? term=vistakon+AND+contact+lens\&rank=6 (accessed on 18 October 2010).

94. ClinicalTrials.gov Evaluation of efficacy and safety of an anti-allergy drug with a contact lens in the treatment of allergic conjunctivitis. Available online: http://clinicaltrials.gov/ct2/show/ NCT00445874?term=vistakon+AND+contact+lens\&rank=7 (accessed on 18 October 2010).

95. SEED. Available online: http://jds.jasdaq.co.jp/documents/tekiji/TD0SCJ2MWUUBKDAA.PDF (accessed on 18 October 2010).

96. Macoul, K.L.; Pavan-Langston, D. Pilocarpine ocusert system for sustained control of ocular hypertension. Arch. Ophthalmol. 1975, 93, 587-590.

97. Saettone, M.F.; Salminen, L. Ocular inserts for topical delivery. Adv. Drug Del. Rev. 1995, 16, 95-106.

98. Sihvola, P.; PuustjäRvi, T. Practical problems in the use of Ocusert ${ }^{\circledR}$-pilocarpine delivery system. Acta Ophthalmol. 1980, 58, 933-937.

99. Aton Pharma Inc. Lacrisert ${ }^{\circledR}$ (Hydroxypropylcellulose ophthalmic insert). Available online: http://www.lacrisert.com/ECP/pdfs/Lacrisert_PI.pdf (accessed on 18 October 2010).

100. Bawa, R. Ocular inserts. In Ophthalmic Drug Delivery Systems; Mitra. A.K., Ed.; Marcell Dekker, Inc.: New York, NY, USA, 1993; pp. 223-260.

101. Huang, T.C.; Lee, D.A. Punctal occlusion and topical medications for glaucoma. Am. J. Ophthalmol. 1989, 107, 151-155.

102. Ariturk, N.; Oge, I.; Erkan, D.; Sullu, Y.; Sahin, M. The effects of nasolacrimal canal blockage on topical medications for glaucoma. Acta Ophthalmol. Scand. 1996, 74, 411-413.

103. Bartlett, J.D.; Boan, K.; Corliss, D.; Gaddie, I.B. Efficacy of silicone punctal plugs as adjuncts to topical pharmacotherapy of glaucoma - a pilot study. Punctal Plugs in Glaucoma Study Group. J. Am. Optom. Assoc. 1996, 67, 664-668.

104. QLT Inc QLT announces phase II clinical trial results and development plans for the punctal plug delivery system. Available online: http:/www.qltinc.com/newsCenter/documents/ 100310a.pdf (accessed on 18 October 2010).

105. ClinicalTrials.gov Safety and efficacy of a glaucoma drug delivery system. Available online: http://clinicaltrials.gov/ct2/show/study/NCT00824720?term=vistakon\&rank=49 (accessed on 18 October 2010). 
106. Kim, H.; Csaky, K.G.; Gilger, B.C.; Dunn, J.P.; Lee, S.S.; Tremblay, M.; de Monasterio, F.; Tansey, G.; Yuan, P.; Bungay, P.M.; Lutz, R.J.; Robinson, M.R. Preclinical evaluation of a novel episcleral cyclosporine implant for ocular graft-versus-host disease. Invest. Ophthalmol. Vis. Sci. 2005, 46, 655-662.

107. Gilger, B.C.; Moore, C.P.; Narfstrom, K.; Liu, J.; Lawson, C.; Cacek, T.; Anglade, E.; Velagaleti, P. Preclinical acute toxicity and pharmacokinetics of episcleral LX201 implants in rabbits. In Proceedings of ARVO 2008 Annual Meeting, Jersey City, NJ, USA, 27 April-1 May 2008; Program number 1964.

108. ClinicalTrials.gov Study to assess LX201 for prevention of corneal allograft rejection or grant failure in subjects who have experienced one or more rejection episodes following penetrating keratoplasty. Available online: http://clinicaltrials.gov/ct2/show/NCT00447642?term=LX-201 \&rank=2 (accessed on 18 October 2010).

109. EuroTimes Episcleral implants could make eye injections obsolete. Available online: http://www.eurotimes.org/09November/episcleralimplants.pdf (accessed on 18 October 2010).

110. Pontes de Carvalho, R.A.; Krausse, M.L.; Murphree, A.L.; Schmitt, E.E.; Campochiaro, P.A.; Maumenee, I.H. Delivery from episcleral exoplants. Invest. Ophthalmol. Vis. Sci. 2006, 47, 4532-4539.

111. ClinicalTrials.gov Safety study of latanoprost slow release insert (Latanoprost SR). Available online: http://clinicaltrials.gov/ct2/show/NCT01180062 (accessed on 18 October 2010).

112. pSivida Products \& Technology. Available online: http://www.psivida.com/products.html (accessed on 18 October 2010).

113. Bausch \& Lomb Vitrasert ${ }^{\circledR}$ (ganciclovir intravitreal implant) $4.5 \mathrm{mg}$. Available online: http://www.bausch.com/en_US/ecp/pharma/product/vitrasert.aspx (accessed on 18 October 2010).

114. Bausch \& Lomb Vitrasert ${ }^{\circledR}$ Sterile Intravitreal Implant with Cytovene ${ }^{\circledR}$ (ganciclovir, $4.5 \mathrm{mg}$ ). Available online: http://www.bausch.com/en_US/package_insert/surgical/vitrasert_pkg_insert.pdf (accessed on 18 October 2010).

115. Jaffe, G.J.; Ben-Nun, J.; Guo, H.; Dunn, J.P.; Ashton, P. Fluocinolone acetonide sustained drug delivery device to treat severe uveitis. Ophthalmology 2000, 107, 2024-2033.

116. Jaffe, G.J.; McCallum, R.M.; Branchaud, B.; Skalak, C.; Butuner, Z.; Ashton, P. Long-term follow-up results of a pilot trial of a fluocinolone acetonide implant to treat posterior uveitis. Ophthalmology 2005, 112, 1192-1198.

117. Jaffe, G.J.; Martin, D.; Callanan, D.; Pearson, P.A.; Levy, B.; Comstock, T. Fluocinolone acetonide implant (Retisert) for noninfectious posterior uveitis: Thirty-four-week results of a multicenter randomized clinical study. Ophthalmology 2006, 113, 1020-1027.

118. Bausch \& Lomb Retisert ${ }^{\circledR}$ (fluocinolone acetonide intravitreal implant) $0.59 \mathrm{mg}$. Available online: http://www.bausch.com/en_US/downloads/ecp/pharma/general/retisert_prescinfopdf.pdf (accessed on 18 October 2010).

119. Kane, F.E.; Burdan, J.; Cutino, A.; Green, K.E. Iluvien: A new sustained delivery technology for posterior eye disease. Expert Opin. Drug Deliv. 2008, 5, 1039-1046. 
120. Campochiaro, P.A.; Hafiz, G.; Shah, S.M.; Bloom, S.; Brown, D.M.; Busquets, M.; Ciulla, T.; Feiner, L.; Sabates, N.; Billman, K.; Kapik, B.; Green, K.; Kane, F. Sustained ocular delivery of fluocinolone acetonide by an intravitreal insert. Ophthalmology 2010, 117, 1393-1399 e1393.

121. Alimera Sciences Alimera Sciences submits Iluvien ${ }^{\circledR}$ NDA to the FDA for the treatment of diabetic macular edema. Available online: http://investor.alimerasciences.com/releasedetail.cfm? RELEASEID=483444\& (accessed on 18 October 2010).

122. ClinicalTrials.gov The MAP Study: Fluocinolone acetonide (FA)/Medidur ${ }^{\mathrm{TM}}$ for age related macular degeneration (AMD) Pilot. Available online: http://clinicaltrials.gov/ct2/show/ NCT00605423?term=Iluvien\&rank=12 (accessed on 18 October 2010).

123. ClinicalTrials.gov Fluocinolone acetonide intravitreal inserts in geographic atrophy. Available online: http://clinicaltrials.gov/ct2/show/NCT00695318?term=Iluvien\&rank=15 (accessed on 18 October 2010).

124. ClinicalTrials.gov Fluocinolone acetonide intravitreal inserts for vein occlusion in retina (FAVOR). Available online: http://clinicaltrials.gov/ct2/show/NCT00770770?term=Iluvien\&rank=9 (accessed on 18 October 2010).

125. Allergan Ozurdex ${ }^{\circledR}$ (dexamethasone intravitreal implant) $0.7 \mathrm{mg}$. Available online: http://www.ozurdex.com/HCP/Default.aspx (accessed on 18 October 2010).

126. Haller, J.A.; Bandello, F.; Belfort, R., Jr.; Blumenkranz, M.S.; Gillies, M.; Heier, J.; Loewenstein, A.; Yoon, Y.H.; Jacques, M.L.; Jiao, J.; Li, X.Y.; Whitcup, S.M. Randomized, sham-controlled trial of dexamethasone intravitreal implant in patients with macular edema due to retinal vein occlusion. Ophthalmology 2010, 117, 1134-1146 e1133.

127. Allergan Allergan receives FDA approval for Ozurdex ${ }^{\circledR}$ as treatment option for non-infectious uveitis affecting the posterior segmjent of the eye. Available online: http://agn.client.shareholder.com/releasedetail.cfm?ReleaseID=511060 (accessed on 18 October 2010).

128. ClinicalTrials.gov A study of the safety and efficacy of a new treatment for diabetic macular edema. Available online: http://clinicaltrials.gov/ct2/show/NCT00168389?term=diabetic +macular+edema+dexamethasone\&rank=1 (accessed on 18 October 2010).

129. Lonngren, U.; Napankangas, U.; Lafuente, M.; Mayor, S.; Lindqvist, N.; Vidal-Sanz, M.; Hallbook, F. The growth factor response in ischemic rat retina and superior colliculus after brimonidine pre-treatment. Brain Res. Bull 2006, 71, 208-218.

130. Kim, H.S.; Chang, Y.I.; Kim, J.H.; Park, C.K. Alteration of retinal intrinsic survival signal and effect of alpha2-adrenergic receptor agonist in the retina of the chronic ocular hypertension rat. Vis. Neurosci. 2007, 24, 127-139.

131. Azadi, S.; Johnson, L.E.; Paquet-Durand, F.; Perez, M.T.; Zhang, Y.; Ekstrom, P.A.; van Veen, T. CNTF+BDNF treatment and neuroprotective pathways in the rd1 mouse retina. Brain Res. 2007, 1129, 116-129.

132. Zhang, M.; Mo, X.; Fang, Y.; Guo, W.; Wu, J.; Zhang, S.; Huang, Q. Rescue of photoreceptors by BDNF gene transfer using in vivo electroporation in the RCS rat of retinitis pigmentosa. Curr. Eye Res. 2009, 34, 791-799. 
133. ClinicalTrials.gov Safety and efficacy of brimonidine intravitreal implant in patients with geographic atrophy due to age-related macular degeneration (AMD). Available online: http://clinicaltrials.gov/ct2/show/NCT00658619 (accessed on 18 October 2010).

134. ClinicalTrials.gov An exploratory study to evaluate the safety of brimonidine intravitreal implant in patients with retinitis pigmentosa. Available online: http://clinicaltrials.gov/ct2/show/ NCT00661479 (accessed on 18 October 2010).

135. SurModics I-vation ${ }^{\mathrm{TM}}$ Sustained Drug Delivery System: Intravitreal Implant for Frug Delivery. Available online: http://www.surmodics.com/pdf/ophthalmology.pdf (accessed on 18 October 2010).

136. Dugel, P.U.; Eliott, D.; Cantrill, H.L.; Mahmoud, T.; Avery, R.; Erickson, S.R. I-Vation ${ }^{\mathrm{TM}}{ }^{\mathrm{TA}}$ 24-month clinical results of the Phase I safety and preliminary efficacy study. In Proceedings of ARVO 2009Annual Meeting, Fort Lauderdale, FL, USA, 3-7 May 2009; E-Abstract 4332.

137. Emerich, D.F.; Thanos, C.G. NT-501: An ophthalmic implant of polymer-encapsulated ciliary neurotrophic factor-producing cells. Curr. Opin. Mol. Ther. 2008, 10, 506-515.

138. Sieving, P.A.; Caruso, R.C.; Tao, W.; Coleman, H.R.; Thompson, D.J.; Fullmer, K.R.; Bush, R.A. Ciliary neurotrophic factor (CNTF) for human retinal degeneration: phase I trial of CNTF delivered by encapsulated cell intraocular implants. Proc. Natl. Acad. Sci. USA 2006, 103, 3896-3901.

139. Jaffe, G.J.; Tao, W.; Group, C.S. A Phase 2 study of encapsulated CNTF-secreting cell implant (NT-501) in patients with geographic atrophy associated with dry AMD-18 month results. In Proceedings of ARVO 2010 Annual Meeting, Fort Lauderdale, FL, USA, 2-6 May 2010; E-Abstract 6415.

140. Neurotech Wet AMD. Available online: http://www.neurotechusa.com/clinical_programs/ wet_amd.asp (accessed on 18 October 2010).

141. Wong, V.; Wood, L. Conveniently Implantable Sustained Release Drug Compositions. U.S. Patent WO2006/039336, 6 April 2006.

142. Lim, J.I.; Hung, D.; Fung, A.E.; Wieland, M.; Wong, V. One year results of a Phase 1 study evaluating the safety and evidence of efficacy of a single intravitreal injection of the VerisomeTM liquid drug delivery system for sustained release of low-dose triamcinolone (IBI-20089) in eyes with cystoid macular edema. In Proceedings of ARVO 2010 Annual Meeting, Fort Lauderdale, FL, USA, 2-6 May 2010; E-Abstract 6396.

143. ClinicalTrials.gov IBI 20089+Lucentis combo intravitreal injections for treatment of neovascular age-related macular degeneration (AMD) (Icon Combo). Available online: http://clinicaltrials.gov/ct2/show/NCT01175395?term=IBI20089\&rank=1 (accessed on 18 October 2010).

144. Cardillo, J.A.; Souza-Filho, A.A.; Oliveira, A.G. Intravitreal bioerudivel sustained-release triamcinolone microspheres system (RETAAC). Preliminary report of its potential usefulnes for the treatment of diabetic macular edema. Arch. Soc. Esp. Oftalmol. 2006, 81, 675-682.

145. Novagari Pharma SA Eyeject ${ }^{\circledR}$. Available online: http://www.novagali.com/en/our-research/ eyeject/ (accessed on 18 October 2010). 
146. ClinicalTrials.gov Safety and tolerability of NOVA63035 "Corticosteroid" in patients with diabetic macular edema secondary to diabetic retinopathy. Available online: http://clinicaltrials.gov/ct2/show/NCT00665106?term=NOVA63035\&rank=1 (accessed on 18 October 2010)

147. Ogura, Y.; Guran, T.; Shahidi, M.; Mori, M.T.; Zeimer, R.C. Feasibility of targeted drug delivery to selective areas of the retina. Invest. Ophthalmol. Vis. Sci. 1991, 32, 2351-2356.

148. Ogura, Y.; Guran, T.; Takahashi, K.; Zeimer, R. Occlusion of retinal vessels using targeted delivery of a platelet aggregating agent. Br. J. Ophthalmol. 1993, 77, 233-237.

149. Pradhan, P.; Banerjee, R.; Bahadur, D.; Koch, C.; Mykhaylyk, O.; Plank, C. Targeted magnetic liposomes loaded with doxorubicin. Methods Mol. Biol. 2010, 605, 279-293.

150. QLT Ophthalmics Visudyne ${ }^{\circledR}$. Available online: http://www.visudyne.com/ (accessed on 18 October 2010).

151. Allison, B.A.; Pritchard, P.H.; Levy, J.G. Evidence for low-density lipoprotein receptor-mediated uptake of benzoporphyrin derivative. Br. J. Cancer 1994, 69, 833-839.

152. Amin, K.; Wasan, K.M.; Albrecht, R.M.; Heath, T.D. Cell association of liposomes with high fluid anionic phospholipid content is mediated specifically by LDL and its receptor, LDLr. $J$ Pharm. Sci. 2002, 91, 1233-1244.

153. Yamaguchi, M.; Yasueda, S.; Isowaki, A.; Yamamoto, M.; Kimura, M.; Inada, K.; Ohtori, A. Formulation of an ophthalmic lipid emulsion containing an anti-inflammatory steroidal drug, difluprednate. Int. J. Pharm. 2005, 301, 121-128.

154. Nakano, S.; Yamamoto, T.; Kirii, E.; Abe, S.; Yamashita, H. Steroid eye drop treatment (difluprednate ophthalmic emulsion) is effective in reducing refractory diabetic macular edema. Graefes. Arch. Clin. Exp. Ophthalmol. 2010, 248, 805-810.

155. Eljarrat-Binstock, E.; Raiskup, F.; Frucht-Pery, J.; Domb, A.J. Transcorneal and transscleral iontophoresis of dexamethasone phosphate using drug loaded hydrogel. J. Control. Release 2005, 106, 386-390.

156. Eyegate Pharmaceuticals EyeGate Pharma Initiates ALLUVION Phase III Study of EGP-437 in Patients with Dry Eye Syndrome. Available online: http://www.eyegatepharma.com/pdf/ news2010/EyegatePR_DES_Ph\%20III_Final.pdf (accessed on 18 October 2010).

157. ClinicalTrials.gov Safety and efficacy study of EGP-437 (Dexamethasone phosphate formulated for ocular iontophoresis) to treat dry eye. Available online: http://clinicaltrials.gov/ct2/show/ NCT01129856?term=EyeGate\&rank=3 (accessed on 18 October 2010).

158. ClinicalTrials.gov Safety and efficacy study of iontophoresis and dexamethasone phosphate to treat anterior uveitis. Available online: http://clinicaltrials.gov/ct2/show/NCT00694135? term=EyeGate\&rank=4 (accessed on 18 October 2010).

159. Singh, R.P.; Mathews, M.E.; Kaufman, M.; Riga, A. Transcleral delivery of triamcinolone acetonide and ranibizumab to retinal tissues using macroesis. Br. J. Ophthalmol. 2010, 94, 170-173.

160. Buckeye Pharmaceuticals Macroesis ${ }^{\mathrm{TM}}$. Available online: http://www.buckeyepharmaceuticals. com/macroesis.htm (accessed on 18 October 2010).

161. Lo, R.; Li, P.Y.; Saati, S.; Agrawal, R.N.; Humayun, M.S.; Meng, E. A passive MEMS drug delivery pump for treatment of ocular diseases. Biomed. Microdev. 2009, 11, 959-970. 
162. Avery, R.L.; Saati, S.; Journey, M.; Caffey, S.; Varma, R.; Tai, Y.C.; Humayun, M.S. A novel implantable, refillable pump for intraocular drug delivery. In Proceedings of ARVO 2010 Annual Meeting, Fort Lauderdale, FL, USA, 2-6 May 2010; E-Abstract 3799.

163. Flanigan, J. Biotech tries to shrug off setbacks. The New York Times 17 September 2009. Available online: http://www.nytimes.com/2009/09/17/business/smallbusiness/17edge.html (accessed on 18 October 2010).

(C) 2011 by the authors; licensee MDPI, Basel, Switzerland. This article is an open access article distributed under the terms and conditions of the Creative Commons Attribution license (http://creativecommons.org/licenses/by/3.0/). 